\title{
Modeling of the Interactions Between Catalytic Surfaces and Gas-Phase
}

\author{
Olaf Deutschmann
}

Received: 13 October 2014/Accepted: 12 November 2014/Published online: 27 November 2014

(c) Springer Science+Business Media New York 2014

\begin{abstract}
The catalytic surface interacts with the gasphase by a variety of chemical and physical processes. Hence, optimization of design and operation conditions of catalytic reactors do not only require the understanding of the catalytic reaction sequence but also its coupling with mass and heat transport and potential homogeneous reactions. The chemical, thermal, and mass-transport interactions between the catalytic surface and the gas-phase are discussed in terms of the individual and combined interactions. The state-of-the-art modelling of reactive flows and its coupling with the catalytic surface is summarized. The interactions are illustrated by a number of examples such as reforming of hydrocarbons, catalytic combustion, exhaust-gas after-treatment, each focusing on a special aspect of catalyst-gas interactions. The potentials and limitations of the numerical simulations will be discussed including experimental techniques for model validation.
\end{abstract}

Keywords Heterogeneous catalysis - Gas-phase kinetics · Surface reaction kinetics - Auto-thermal reforming .

Combustion · Partial oxidation · Kinetic modeling

\section{Introduction}

The interaction of the catalytic surface with the gas phase in heterogeneous catalysis implies much more than the simple

O. Deutschmann $(\bowtie)$

Institute for Chemical Technology and Polymer Chemistry,

Karlsruhe Institute of Technology (KIT), Engesserstr. 20,

Karlsruhe 76131, Germany

e-mail: deutschmann@kit.edu textbook scheme of providing reactants and delivering the products by mass diffusion. A variety of physical and chemical processes in the gas-phase of a catalytic reactor influences conversion and selectivity as well as short and long-term catalyst performance. Catalytic monoliths can serve as an example. They are frequently used for the reduction of pollutant emissions from automobiles [1], selective oxidation [2-4] and reforming of hydrocarbons [5, 6], and combustion of natural gas [7-9]. Figure 1 illustrates the physics and chemistry in a catalytic combustion monolith that glows at a temperature of about $1,300 \mathrm{~K}$ due to the exothermic oxidation reactions. In each channel of the monolith, the transport of momentum, energy, and chemical species occurs not only in flow (axial) direction, but also in radial direction. The reactants diffuse to the inner channel wall, which is coated with a porous structure (washcoat) supporting the catalytic material, through which gaseous species diffuse to eventually react on the catalytic particle. The products and intermediates desorb and diffuse back into the bulk flow. Due to the high temperatures, the chemical species may also react homogeneously in the gas phase. The temperature distribution depends on the interaction of heat convection and conduction in the fluid, heat release due to chemical reactions, heat transport in the solid material, and thermal radiation. Temporarily and spatially varying feed composition and heat transfer between reactor and ambience will cause a non-uniform temperature distribution over the entire monolith, and the behavior will differ from channel to channel. The catalyst itself may be modified in time by interaction with species from the gas phase; the catalytic particles can be oxidized, reduced, aged, poisoned, regenerated, evaporated etc.

A variety of chemical and physical interactions of processes in the gas-phase with the catalytic surfaces are sketched in a more systematic way in Fig. 2. The obvious 
Fig. 1 Catalytic combustion monolith and physical and chemical process occurring in the single monolith channel; reproduced with permission from Janardhanan and Deutschman [128]

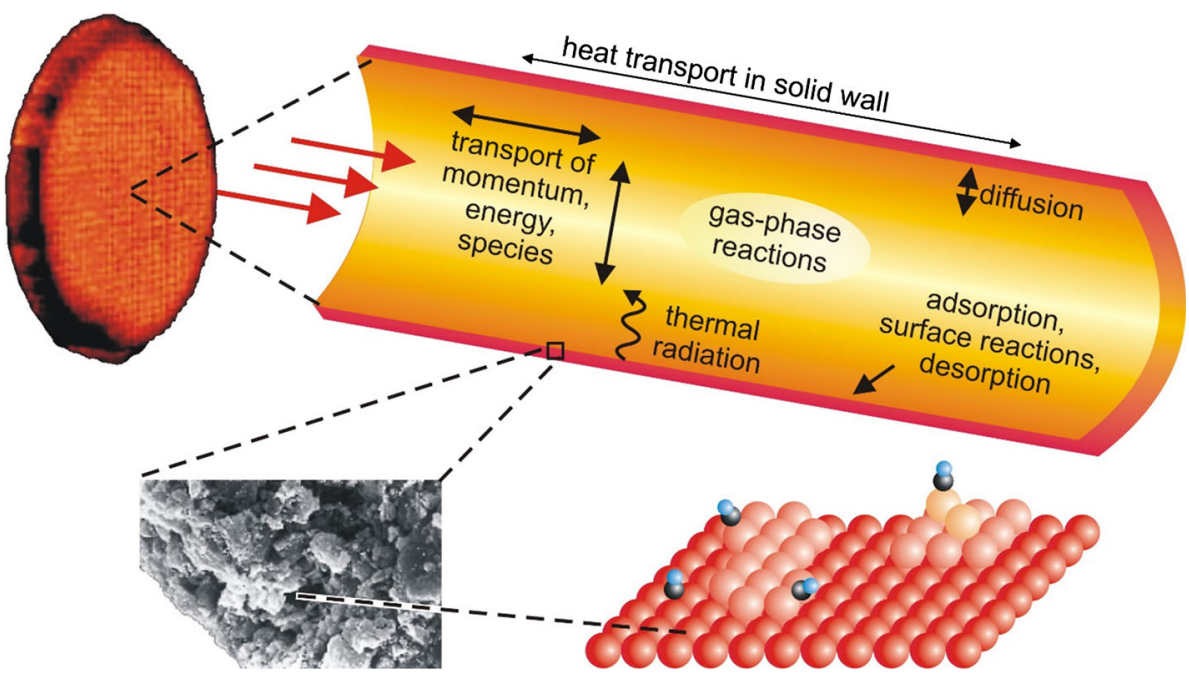

Fig. 2 Sketch of possible interactions between catalytic surface and gas-phase and in heterogeneously catalyzed gasphase reactions

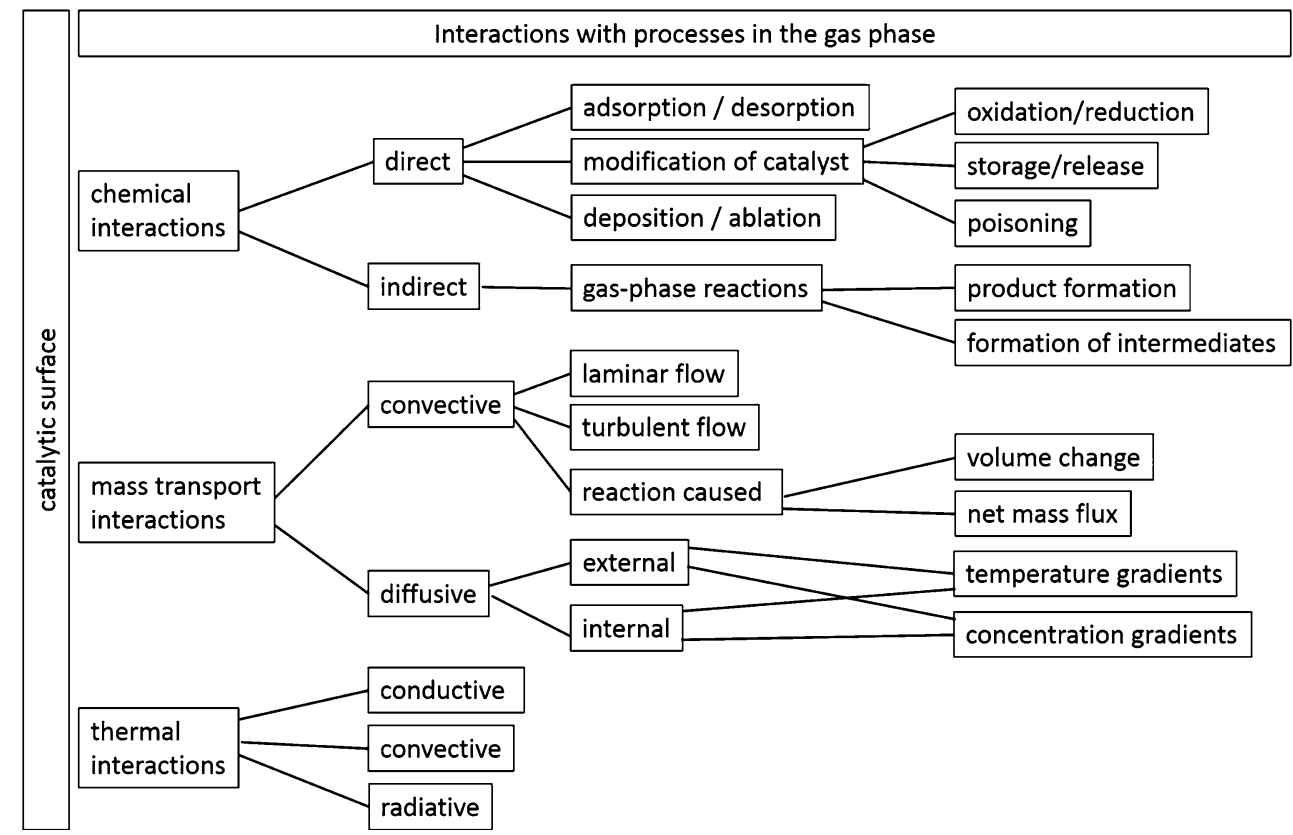

direct chemical interaction of the gas-phase with the catalytic surface is the adsorption of reactants from and desorption of products to the gas phase. However, intermediates formed on the surface may desorb as well and readsorb. Examples are the water molecule in partial oxidation of alkanes over noble metals $[10,11]$ and $\mathrm{NO}_{2}$ in $\mathrm{NO}_{\mathrm{x}}$ storage catalysts $[12,13]$. Desorbing intermediates and radicals may trigger chemical reactions in the gas-phase and by this open a competing reaction pathway. For instance, desorbing $\mathrm{OH}$ from $\mathrm{Pt}$ can enhance homogeneous ignition in the gas phase in catalytically supported combustion [14]. On the other hand, adsorbing radicals may quench chemical reactions in the gas-phase such as in the suppression of explosions in catalytic micro reactors [15].
Depending on the species' partial pressures in the gas phase a strong adsorbate may cover the entire catalytic surface and inhibit catalytic reactions (CO on $\mathrm{Pt}$ in lowtemperature fuel cells) [16]. Oxidizing and reducing species may lead to oxidation (reduction) of the few top monolayers of the catalyst and even oxidize (reduce) the entire catalytic particle. Examples are $\mathrm{CO}$ oxidation [17] as well as partial and selective oxidation of hydrocarbons over noble metals and metal oxides. Here catalyst size and morphology as well as support and additives matter as well. The catalyst oxidation state may change in time, e.g. due to higher temperature caused by the ignition of an exothermic reaction such as in reduction of $\mathrm{Rh}$ in partial oxidation of methane [18] or due to the availability of a catalytically 
formed product such as in the oxidation of $\mathrm{Pt}$ with $\mathrm{NO}_{2}$ in diesel oxidation catalysts [19]. Depending on the surrounding gas-phase the catalyst may need an initiation time to reach the state of catalytic activity such as in FischerTropsch catalysts [20]. The catalyst may also store certain gaseous components and release them upon modified conditions in the gas-phase such as $\mathrm{NO}_{\mathrm{x}}$ storage catalysts $[21,22]$. Adsorbed species can undergo structural changes leading to undesired deposits such as carbonaceous overlayers, e.g. catalyst coking by the Boudouard reaction, and sulfates, e.g. in exhaust-gas cleaning, which eventually stops the catalytic cycle. However, blocking of catalytic sites may be selective and by this open alternate beneficial reaction pathways. Chemical reactions in the gas-phase may produce species that potentially threat the catalyst cycle when deposited on the surface such as in coking of catalysts due to gas-phase molecular growth processes [23]. Gas-phase species may lead to catalyst loss due to evaporation at lower temperatures upon oxidation of the catalyst. Homogeneous gas-phase reactions may also produce gas-phase species that then interact with the catalytic cycle: For instance, olefins and aldehydes are formed in the gas-phase in partial oxidation of propane [24] and ethanol [25], respectively, over $\mathrm{Rh}$; these species are then converted catalytically again. Catalytic conversion may trigger desired homogeneous gas-phase reactions such as in the formation of olefins in oxy-dehydrogenation of alkanes over Pt [24, 26, 27].

Aside from the chemical interactions between gas-phase and catalytic surface, physical interactions occur by mass and heat transfer. The optimization of mass and heat transfer are decisive steps to transfer a novel catalytic process from the laboratory to the technical scale. On the larger length scale, the convective flow determines the transport of reactants and products in the catalytic reactor. When pressure drop becomes an issue, laminar flows are preferred, e.g. in automotive catalytic converters. When mixing is of more importance, then turbulent flow is beneficial, e.g. in fluidized beds. On a much smaller length scale, convective transport can be introduced by catalytic reactions with large volumetric changes (e.g. in cracking of hydrocarbons) and by net mass fluxes at the surface (e.g. in chemical vapor deposition, combustion of solids, etching, ignition of catalytic reactions).

The overall reaction rate is often limited by diffusion processes and not by the intrinsic turn-over-frequency. At intermediate temperatures, internal diffusion in the pores of the catalytic structure matters. In automotive catalytic converters, the reduced overall conversion due to internal mass transfer limitations at intermediate temperatures [28, 29] is a threat for licensing the devices, because any legislative test cycle covers this temperature range in the first few minutes after cold start-up of the engine. At higher temperatures, external diffusion in the catalyst-near gas-phase becomes the rate-limiting step. Diffusive transport may also be introduced by temperature gradients, significant for instance in catalytic reformers for hydrogen production or catalytic sensors for detection of hydrogen gases.

Thermal interactions between catalytic surfaces and the surrounding gas-phase do not only occur due to the reaction enthalpy and the heat needed to be transported from (exothermic reaction) and to (endothermic reaction) the catalyst but also due to varying external conditions (e.g. in automotive catalytic converters). Conductive and convective heat transport in the gas phase can significantly influence the catalytic conversion indirectly aside from conductive heat transport in the solid structure and radiative heat transfer.

Aside from experimental studies, modeling and numerical simulations can significantly support our understanding of the interactions between the gas phase and the catalytic surface. Actually, numerical simulations are more and more used as the only tractable tool to study the complex coupling between flow, mass and heat transfer and multi-phase chemical reactions in the process of designing and optimizing of technical catalytic reactors. Modeling and simulation over the years became a decisive toolbox in saving the engineers' costs and time in scale-up of the catalytic process. In the next two sections, the current approaches of modeling of gas-surface interactions will summarized also giving the fundamental governing equations for reactive flows. In the remainder, several studies from literature will be discussed to highlight certain aspects of the interactions between catalytic surface and gas phase. This article will neither consider molecular simulations such as Density Functional Theory (DFT), Molecular Dynamics (MD), and MonteCarlo (MC) simulations nor liquid and three-phase flows, for which it is referred to the literature, e.g. for multi-scale modeling of heterogeneously catalyzed gas-phase reactions [30] and for three-phase flow modeling [31-33].

\section{Modeling of Gaseous Reactive Flows}

\subsection{Governing Equations for Multi-component Reactive Flows}

As long as a fluid can be treated as continuum, the most accurate description of the flow field of multi-component mixtures is given by the transient three-dimensional (3D) Navier-Stokes equations coupled with the energy and species governing equations [34-38]. Alternative concepts such as Lattice-Boltzmann models (LBM) [39, 40] are still difficult to handle in multi-component mixtures but are promising for the simulation of complex flow structures for instance in fixed beds [41-43]; they will not be covered here. 
Governing equations, which are based on conservation principles, can be derived by consideration of the flow within a certain spatial region, which is called the control volume. The principle of mass conservation then leads to the mass continuity equation

$\frac{\partial \rho}{\partial t}+\frac{\partial\left(\rho v_{i}\right)}{\partial x_{i}}=S_{\mathrm{m}}$

with the mass density $\rho$, the time $t$, Cartesian coordinates $x_{i}$ $(i=1,2,3)$, velocity components $v_{i}$. The source term $S_{\mathrm{m}}$ vanishes unless mass is either deposited on or ablated from the solid surfaces (e.g. chemical vapor deposition, filters, etching, combustion of solids). The Einstein convention is used here, i.e., whenever the same index appears twice in any term, summation over that index is implied, except if the index refers to a chemical species. The principle of momentum conservation for Newtonian fluids leads to three scalar equations for the momentum components $\rho v_{i}$

$\frac{\partial\left(\rho v_{i}\right)}{\partial t}+\frac{\partial\left(\rho v_{i} v_{j}\right)}{\partial x_{j}}+\frac{\partial p}{\partial x_{i}}+\frac{\partial \tau_{i j}}{\partial x_{j}}=\rho g_{i}$

With the static pressure $p$, stress tensor $\tau_{i j}$, gravity $g_{i}$. The stress tensor can be written as

$\tau_{i j}=-\mu\left(\frac{\partial v_{i}}{\partial x_{j}}+\frac{\partial v_{j}}{\partial x_{i}}\right)+\left(\frac{2}{3} \mu-\kappa\right) \delta_{i j} \frac{\partial v_{k}}{\partial x_{k}}$,

with bulk and mixture viscosities, $\kappa$ and $\mu$, respectively. The coupled mass continuity and momentum governing equations have to be solved for the description of the flow field.

In multi-component mixtures, not only the flow field is of interest but also mixing of the chemical species and reactions among them, which can be described by an additional set of partial differential equations. Here, the mass $m_{i}$ of each of the $N_{\mathrm{g}}$ gas-phase species obeys a conservation law

$\frac{\partial\left(\rho Y_{i}\right)}{\partial t}+\frac{\partial\left(\rho v_{j} Y_{i}\right)}{\partial x_{j}}+\frac{\partial\left(j_{i, j}\right)}{\partial x_{j}}=R_{i}^{\text {hom }}$,

where $Y_{i}$ is the mass fraction of species $i$ in the mixture $\left(Y_{i}=m_{i} / m\right)$ and $m$ the total mass. $R_{i}^{\text {hom }}$ is the net rate of production due to homogeneous chemical reactions in the gas phase. The components $j_{i, j}$ of the diffusion mass flux caused by concentration and temperature gradients are often modeled by the mixture-average formulation [44]:

$j_{i, j}=-\rho \frac{Y_{i}}{X_{i}} D_{i}^{M} \frac{\partial X_{i}}{\partial x_{j}}-\frac{D_{i}^{T}}{T} \frac{\partial T}{\partial x_{j}}$.

$D_{i}^{\mathrm{M}}$ is the effective diffusion coefficient of species $i$ in the mixture, $D_{i}^{\mathrm{T}}$ is the thermal diffusion coefficient, which is significant only for light species, and $T$ is the temperature. The molar fraction $X_{i}$ is related to the mass fraction $Y_{i}$ using the species molar masses $M_{i}$ by
$X_{i}=\frac{1}{\sum_{j=1}^{N g} Y_{j} / M_{j}} \frac{Y_{i}}{M_{i}}$

Heat transport and heat release due to chemical reactions lead to spatial and temporal temperature distributions in catalytic reactor. The corresponding governing equation for energy conservation is commonly expressed in terms of the specific enthalpy $h$ :

$\frac{\partial(\rho h)}{\partial t}+\frac{\partial\left(\rho v_{j} h\right)}{\partial x_{j}}+\frac{\partial j_{q, j}}{\partial x_{j}}=\frac{\partial p}{\partial t}+v_{j} \frac{\partial p}{\partial x_{j}}-\tau_{j k} \frac{\partial v_{j}}{\partial x_{k}}+S_{h}$,

with the heat source $S_{\mathrm{h}}$, e.g. due to thermal radiation. In multi-component mixtures, diffusive heat transport is significant due to heat conduction and mass diffusion, i.e.

$j_{q, j}=-\lambda \frac{\partial T}{\partial x_{j}}+\sum_{i=1}^{N g} h_{i} j_{i, j}$.

$\lambda$ is the thermal conductivity of the mixture. The temperature is then related to the enthalpy by the definition of the mixture specific enthalpy

$h=\sum_{i=1}^{N g} Y_{i} h_{i}(T)$,

with the specific enthalpy $h_{i}$. Heat transport in solids such as reactor walls and catalyst materials can also be modeled by an enthalpy equation, for instance in the form of

$\frac{\partial(\rho h)}{\partial t}-\frac{\partial}{\partial x_{j}}\left(\lambda \frac{\partial T}{\partial x_{j}}\right)=S_{h}$,

where $h$ is the specific enthalpy and $\lambda$ the thermal conductivity of the solid material. $S_{\mathrm{h}}$ accounts for heat sources.

This system of governing equations is closed by the equation of state to relate the thermodynamic variables $\rho$, $p$, and $T$, the simplest model being the ideal gas equation

$p=\frac{\rho R T}{\sum_{i=1}^{N_{g}} X_{i} M_{i}}$,

with the universal gas constant $R=8.314 \mathrm{~J} \mathrm{~mol}^{-1} \mathrm{~K}^{-1}$.

The transport coefficients $\mu, D_{i}^{\mathrm{M}}, D_{i}^{\mathrm{T}}$, and $\lambda$ appearing in Eqs. $(3,5,8)$ depend on temperature and mixture composition. They can be derived from the transport coefficients of the individual species and the mixture composition by applying empirical approximations [34, 35, 37]. The temperature is commonly implicitly derived from Eq. (9) by

$h_{i}=h_{i}\left(T_{\mathrm{ref}}\right)+\int_{T_{\mathrm{ref}}}^{T} c_{p, i}\left(T^{\prime}\right) d T^{\prime}$,

where $c_{p, i}$ is the specific heat capacity at constant pressure. 
The Eqs. (1-11) can principally be used in the numerical simulation of laminar as well as turbulent flow fields; the so-called Direct Numerical Simulations, DNS. In practice, however, the solution of the Navier-Stokes equations for turbulent flows demands a prohibitive amount of computational time due to the huge number of grid points needed to resolve the small scales of turbulence. Therefore, several concepts were developed to model turbulent flows by the solution of averaged governing equations. However, the equation system is not closed, that means a model has to be set up to describe the so-called Reynold stresses that are the correlations between the velocity fluctuations and the fluctuations of all the quantities of the flow (velocity, enthalpy, mass fractions). The $k-$ $\varepsilon$ - model [45] is one of the most widely used concepts for modeling the Reynold stresses at high Reynolds numbers, which adds two additional partial differential equations for the description of the turbulent kinetic energy, $k$, and the dissipation rate, $\varepsilon$, to the governing equations. Although the model has well-known deficiencies, it is today implemented in most commercial CFD (Computatial Fluid Dynamcis) codes and also widely used for the simulation of catalytic reactors. Modeling of turbulent flows is still a very active field of research. A promising approach is represented by Large-Eddy-Simulations (LES), which combine DNS for the larger scales with a turbulence model, e.g. $k-\varepsilon-$ model, for the unresolved smaller scales. Aside from this closure problem, one still has to specify the averaged chemical reaction rates [37, 46, 47]. Because of the strong non-linearity of the rate coefficients due to the exponential dependence on temperature and the power-law dependence on partial pressures, the source terms of chemical reactions in turbulent flows should never (!) be computed using average concentrations and temperature. Here, probability density functions (PDFs) [37], either derived from transport equations [48] or empirically constructed [49], are used to take the turbulent fluctuations into account when calculating the chemical source terms. For the simulation of reactions on catalysts it is also important to use appropriate models for the laminarization of the turbulent flow near the solid surface [47, 50]. Multi-phase dispersed flows such as in fluidized beds are another class of flow systems in catalytic converters, which is still a very active field of research. Here, it is referred to two excellent books by Marchisio and Fox [51, 52].

\subsection{Modeling Gaseous Transport in Porous Catalysts}

Porous media are present everywhere in catalysis technology such as in fixed-bed reactors, catalytic filters, washcoat layers, perforated plates, flow distributors, tube banks, membranes, electrodes, fiber materials etc. Modeling the transport and reactions in the actual tortuous structure on the microscopic level is a rather formidable task [53-55]. Due to this complexity, it is often necessary to work with small representative volume elements where the porous medium and other properties are assumed to be homogenized. Several methods have been developed to include porous media and reactions in CFD simulations, e.g. an empirically determined flow resistance accounting for the pressure drop, which is a sink in the governing momentum Eq. (2),

$S_{i}=-\left(\frac{\mu}{\alpha} v_{i}+\frac{C}{2} \rho|\vec{v}| v_{i}\right)$

where $\alpha$ is the permeability (Darcy's law) and $C$ is the inertial resistance, which can be viewed as a loss per unit length along the flow direction. Concerning the temperature profile in porous media, the enthalpy Eqs. (7) and (10) have to be adapted. The approach assuming constant unidirectional flow breaks down for fixed bed reactors with reactor diameters less than ten times the particle size. Thus the model cannot predict the velocity maximum in the vicinity of the wall observed experimentally for those reactors [56]. An averaged velocity with a radially varying axial component can be provided by a further modification of the momentum balance [56-58] as an improvement of the classical model. The reader is referred to the textbook by Keil [54] and references therein.

\subsection{Coupling of the Gas-Phase with the Catalytic Surface}

The coupling of the species mass fluxes at the gas-surface interface depends on the spatial size and structure of the catalyst, e.g. flat surface, gauzes, pellets, washcoats.

Infinitely fast internal diffusion usually occurs at low temperatures (kinetically controlled regime) and in rather thin catalyst layers. Then no concentration gradients occur in the porous structure and, hence, its spatial resolution is not needed. If the catalytic structure is spatially-resolved, obtained e.g. by magnetic resonance imaging (MRI) [59], no homogenizing model is needed either. In both cases, the catalytic surface is coupled to the gas-phase by the boundary conditions for the species-continuity Eqs. (4) [34, 60]:

$\vec{n}\left(\vec{j}_{i}+\rho \vec{v}_{\text {Stef }} Y_{i}\right)=R_{i}^{\text {het }}=\frac{A_{\text {cat }}}{A_{\text {geo }}} M_{i} \dot{s}_{i}$

Here $\vec{n}$ is the outward-pointing unit vector normal to the surface, $\vec{j}_{i}$ is the diffusion mass flux of species $i$ as discussed in Eqs. (4), and $R_{i}^{\text {het }}$ is the heterogeneous surface reaction rate (desorption minus adsorption), which is given per unit geometrical surface area, $A_{\text {geo }}$, in $\mathrm{kg} \mathrm{m}^{-2} \mathrm{~s}^{-1}$. The molar net production rate of gas phase species $i, \dot{s}_{i}$, is given in $\mathrm{mol} \mathrm{m}^{-2} \mathrm{~s}^{-1}$; the area now refers to the actual 
catalytically active surface area, $A_{\text {cat }}$, to be determined experimentally, e.g. by chemisorption measurements. The ratio $F_{\text {cat } / \text { geo }}=\frac{A_{\text {cat }}}{A_{\text {geo }}}$ is also used to describe the dependence of the overall reaction rate on catalyst loading and effects of hydro-thermal aging for structure-insensitive catalysts [61]. Practically, it was recently applied to model the performance of on-road aged three-way catalysts [62].

A non-zero Stefan velocity $\vec{v}_{\text {Stef }}$ occurs for net mass flux between the surface and the gas phase:

$\vec{n} \vec{v}_{\text {Stef }}=\frac{1}{\rho} \sum_{i=1}^{N_{g}} R_{i}^{\text {het }}$.

At steady-state conditions, this mass flux vanishes unless mass is deposited on the surface, e.g. chemical vapor deposition, or ablated, e.g. material etching. Equation (14) basically means that for $\vec{v}_{\text {Stef }}=0$ the amount of gas-phase molecules of species $i$, which are consumed/produced at the catalyst by adsorption/desorption, have to diffuse to/ from the catalytic wall (Eq. 5). Only for fast transient $\left(<10^{-4} \mathrm{~s}\right)$ adsorption/desorption processes, e.g. during ignition of catalytic oxidation, Eq. (14) breaks down and special treatment of the coupling is needed [34, 63, 64]. Furthermore, those fast transient processes may lead to heat accumulation terms [63] and also to additional convective transport and associated pressure gradients in the fluid phase above the catalyst [64].

The effectiveness factor approach is the simplest model to account for finite diffusion by scaling the intrinsic reaction rate at the fluid-solid interphase:

$R_{i}^{\text {het }}=\eta \frac{A_{\text {cat }}}{A_{\text {geo }}} M_{i} \dot{s}_{i}$

The effectiveness factor

$\eta_{i}=\frac{\dot{s}_{i, \text { eff }}}{\dot{s}_{i}}$,

with $\dot{s}_{i, \text { eff }}$ as effective surface reaction rate in the porous structure, is based on the Thiele modulus, $\Phi_{i}[38,65]$ :

$\eta_{i}=\frac{\tanh \left(\Phi_{i}\right)}{\Phi_{i}}$ with

$\Phi_{i}=L_{\mathrm{wc}} \sqrt{\frac{\dot{s}_{i} A_{\mathrm{cat}}}{D_{\mathrm{eff}, i} c_{i, 0} V_{\mathrm{wc}}}}$

Here, $L$ is the thickness of the porous medium (washcoat), $V_{\mathrm{wc}}$ the washcoat volume, and $c_{i, 0}$ are the species concentrations at the fluid/porous media interface. Since mass conservation has to be obeyed (Eq. 16), the same effectiveness factor has to be applied for all chemical species. Therefore, this simple model can only be applied at conditions, at which the reaction rate of one species $i$ determines overall reactivity, i.e. in Eq. (16), $\eta=\eta_{i}$.
Furthermore, this model then implies that mass diffusion inside the porous media can be described by the same diffusion coefficient for all species.

In most fixed bed reactors with large numbers of catalytic pellets, for non-trivial shapes of the catalysts, and for catalyst dispersed in porous media, the structure of the catalyst cannot be resolved geometrically. In those cases, the catalytic reaction rate is expressed per volumetric unit, that means $R_{i}^{\text {het }}$ is now given in $\mathrm{kg} \mathrm{m}^{-3} \mathrm{~s}^{-1}$; the volume here refers to the volume of a computational cell in the in the geometrical domain of fluid flow. Then $R_{i}^{\text {het }}$ simply represents an additional source term on the right side of the species-continuity equation, Eq. (4), and is computed by

$R_{i}^{\text {het }}=\eta \frac{A_{\text {cat }}}{V} M_{i} \dot{s}_{i}$,

where $\frac{A_{c a t}}{V}$ is the active catalytic surface area per volumetric unit, given in $\mathrm{m}^{-1}$.

A more sophisticated approach for modeling reactions and diffusion in porous media consists in the solution of a set of reaction-diffusion equations:

$\frac{\partial}{\partial r}\left(-D_{\text {eff }, i} \frac{\partial c_{i}^{\mathrm{wc}}}{\partial r}\right)-\frac{A_{\text {cat }}}{V} \dot{s}_{i}=0$.

Here, $c_{i}^{\mathrm{wc}}$ denotes the species concentration in the washcoat in normal direction to the fluid/washcoat interface. In addition to Eq. (21), the surface coverages, $\theta_{i}(r)$, vary in space.

Fluxes within porous media which are driven by gradients in concentration and pressure, i.e. diffusion and convection, can be described by the Dusty Gas Model (DGM) [54, 66]. This model, which is also applicable for three-dimensional and larger porous media, is superior to the ones discussed above but also leads to large computational efforts.

\section{Modeling the Rates of Chemical Reactions}

\subsection{Surface Reaction Rate}

Since the rate of catalytic reactions is very specific to the catalyst formulation, global rate expressions have been used for many years. These reaction rates are based on catalyst mass, catalyst volume, reactor volume, or catalyst external surface area. The implementation of this macrokinetics approach into reactor simulations is straightforward; the reaction rate can in general be expressed by any arbitrary function of gas-phase concentrations and temperature at the catalysts surface calculated at every computational cell containing either catalytically active particles or walls. It is evident that this approach cannot account for the complex variety of phenomena of catalysis and that the rate parameters must be evaluated 
experimentally for each new catalyst and various external conditions.

The direct computation of surface reaction rates from the molecular situation leads more and more to a comprehensive description, at least for idealized systems. However, DFT, MD, and MC simulations cannot be implemented in complex flow field simulations of technically relevant systems due to missing algorithms and, more importantly, due to the immense amount of computational time needed. Treating the catalytic system as a black box is not the alternative, the knowledge gained from experimental and theoretical surface science studies can be implemented in the chemical models used in reaction engineering simulation. A tractable approach is the treatment of surface chemistry by rate equations [34, 67, 68]. This so-called mean-field approximation (MF) was then first computationally realized in the SURFACE CHEMKIN [60] module of the CHEMKIN [69, 70] software package; later other packages such as CANTERA [71] and DETCHEM [72] as well as many of the commercially available multi-purpose CFD codes adopted this methodology or directly implemented those modules.

The mean field approximation is related to the size of the computational cell in the flow field simulation, assuming that the local state of the active surface can be represented by mean values for this cell. The state of the catalytic surface is described by the temperature $T$ and a set of surface coverages, $\theta_{i}$, depending on time and the meso/ macroscopic position in the reactor, but averaged over microscopic local fluctuations. The surface structure of the catalyst is associated with a surface site density $\Gamma$ that describes the maximum number of species adsorbing on a unit surface area, given, e.g., in $\mathrm{mol} \mathrm{m}^{-2}$. Each surface species is associated with a coordination number $\sigma_{i}$ describing the number of surface sites which are covered by this species. Under the assumptions made, multi-step (quasi-elementary) reaction mechanisms can be set up. The local chemical source term, $R_{i}^{\text {het }}$, is then defined by

$R_{i}^{\text {het }}=\dot{s}_{i} M_{i}=M_{i} \sum_{k=1}^{K_{\mathrm{s}}} v_{i k} k_{f_{k}} \prod_{j=1}^{N_{\mathrm{g}}+N_{\mathrm{s}}+N_{\mathrm{b}}} c_{j}^{v_{j k}^{\prime}}$.

Here, $K_{\mathrm{s}}$ is the number of surface reactions, $c_{\mathrm{i}}$ are the species concentrations, which are given, e.g., in $\mathrm{mol} \mathrm{m} \mathrm{m}^{-2}$ for the $N_{\mathrm{s}}$ adsorbed species and in, e.g., $\mathrm{mol} \mathrm{m}{ }^{-3}$ for the $N_{\mathrm{g}}$ and $N_{\mathrm{b}}$ gaseous and bulk species. According to Eq. (22) and the relation $\Theta_{i}=c_{i} \sigma_{i} \Gamma^{-1}$, the variations of surface coverages follow

$\frac{\partial \Theta_{i}}{\partial t}=\frac{\dot{s}_{i} \sigma_{i}}{\Gamma}$

The variation of the binding states of adsorption due to varying surface coverages can be modelled by an additional coverage dependence $\left(\mu_{i_{k}}, \varepsilon_{i_{k}}\right)$ in the expression for the rate coefficient $k_{f_{x}}$ in Eq. (22) [34, 60, 73]:

$k_{\mathrm{f}_{k}}=A_{k} T^{\beta_{k}} \exp \left[\frac{-E_{\mathrm{a}_{k}}}{R T}\right] \prod_{i=1}^{N_{\mathrm{s}}} \Theta_{i}^{\mu_{i_{k}}} \exp \left[\frac{\varepsilon_{i_{k}} \Theta_{i}}{R T}\right]$

Here, $A_{k}$ is the pre-exponential factor, $\beta_{k}$ is the temperature exponent, $E_{\mathrm{a}_{k}}$ is the activation energy. Because thermodynamic data, in particular entropies, for adsorbes species are difficult measure and compute, thermodynamic consistency of surface kinetics for reaction networks is a crucial issue; two methods have been proposed enforcing thermodynamic consistency without the necessity to know the thermodynamics of all adsorbates explicitly [74, 75].

\subsection{Gas-Phase Reaction Rate}

The rate of elementary reactions in the homogeneous gas phase, $R_{i}^{\text {hom }}$ in Eq. (4), is commonly expressed by

$R_{i}^{\mathrm{hom}}=M_{i} \sum_{k=1}^{K_{g}}\left(v_{i k}^{\prime \prime}-v_{i k}^{\prime}\right) A_{k} T^{\beta_{k}} \exp \left[\frac{-E_{a_{k}}}{R T}\right] \prod_{j=1}^{N_{g}}\left(\frac{Y_{j} \rho}{M_{j}}\right)^{v_{j k}^{\prime}}$.

with the stoichiometric coefficients $v_{j k}^{\prime}$ and $v_{j k}^{\prime \prime}$

Various sets of elementary reactions are available for modeling homogeneous gas phase reactions that may matter in catalytic reactors $[37,76,77]$.

Even though the implementation of Eqs. (22) and (25) into CFD codes is straightforward, an additional highly nonlinear coupling is introduced into the governing equations leading to considerable computational efforts. The nonlinearity, the large number of chemical species, and the fact that chemical reactions exhibit a large range of time scales render the solution of those equation systems challenging. In particular for turbulent flows, but sometimes even for laminar flows, the solution of the system is too CPU time-consuming with current numerical algorithms and computer capacities.

\section{Examples for Interactions Between Catalytic Surface and Gas-Phase}

Recent and challenging numerical simulations of catalytic reactors will be discussed now with an emphasis on the interactions of processes in the gas-phase and on the catalytic surface. The order of the examples will follow the sketch shown in Fig. 2 with a number of different applications. In most examples, however there are multiple interactions between catalyst and gas phase. 


\subsection{Chemical Interactions}

\subsubsection{Adsorption and Desorption: Partial Oxidation of $\mathrm{CH}_{4}$ over $\mathrm{Rh}$}

The most obvious interactions between gas-phase and catalytic surface in heterogeneous catalysis are the adsorption and desorption of reactants and products, respectively. However, depending on the position in the reactor and the time-onstream, the role of the species in the gas-phase can vary. In partial oxidation of hydrocarbons over noble metals in monolithic and fixed bed reactors, steam is formed in the entrance region of the flow reactor due to total oxidation of the hydrocarbons. Then, further downstream, steam becomes a reactant in reforming of the remaining methane, which actually is the major route for hydrogen formation. Figure 3 shows the computed time-resolved temperature and species profiles in a single channel of the catalytic monolith (similar to the one shown in Fig. 1) and the temperature distribution of the solid structure during light-off of the reaction [78]. The numerical simulation is based on a two-dimensional simulation of the flow, temperature, and concentration fields in the catalytic channels using a 38-step catalytic reaction mechanism coupled with a transient three-dimensional simulation of the temperature of the solid structure [72,79]. The species profiles change with space and time: in the beginning and in the entrance region in steady-state, the very exothermic total oxidation occurs. Later due to the higher temperatures and the depletion of oxygen concentration, the formation of hydrogen is conducted by steam reforming over the entire catalyst except in the entrance region where oxygen is still available. When this simulation was conducted only the outlet composition could be measured and compared with the results [78]. In the last decade, in situ techniques have been developed to spatially resolve the species profiles and the catalyst states inside catalytic reactors. Capillary sampling, laser-spectroscopy, and X-ray absorption spectroscopy are today applied to develop and evaluate the models. The reaction scheme used for the simulation shown in Fig. 3 was later tested by Mantzaras et al. [80] to simulate 2D species profiles measured by Raman spectroscopy (Fig. 4). Even though, higher pressure and steam addition was used, the model was able to predict the spatial profiles accurately, also revealing the indirect route to hydrogen via steam reforming.

\subsubsection{Modification of the State of the Catalyst: Partial Oxidation of $\mathrm{CH}_{4}$ over Noble Metals}

The computed surface coverages as function of time (Fig. 5) and axial position for the case discussed above (Fig. 3) reveal that the surface is mainly covered by oxygen implying a higher oxidation state of the catalyst before ignition. During ignition, adsorbed oxygen vanishes except

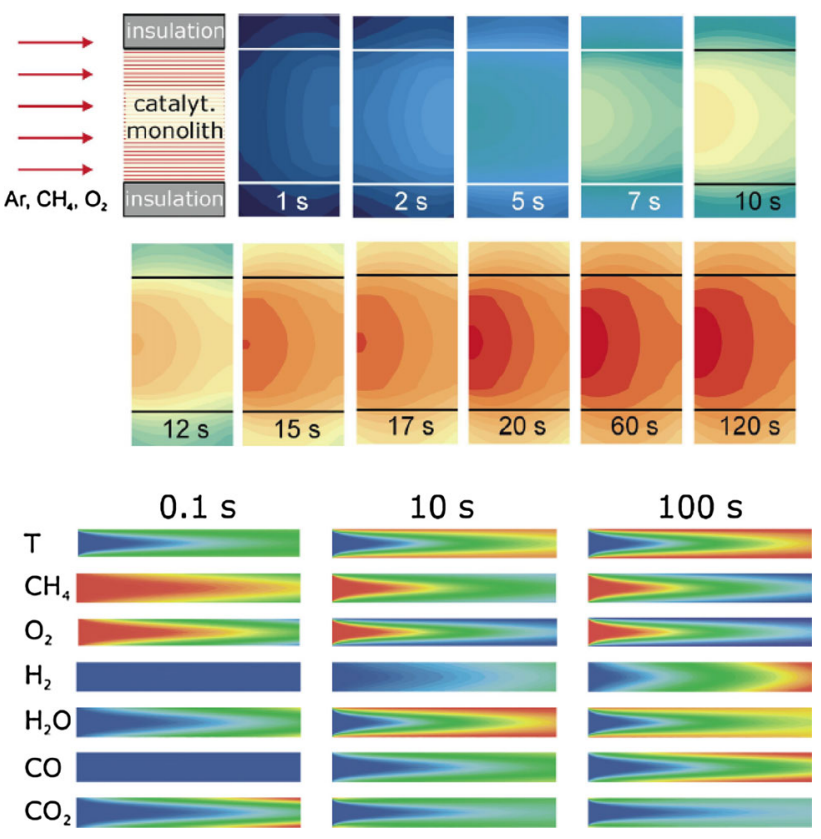

Fig. 3 Numerical simulation of the light-off of a $\mathrm{Rh} / \mathrm{Al}_{2} \mathrm{O}_{3}$ coated monolithic honeycomb reactor coated for partial oxidation of methane to synthesis gas; reprinted with permission from Elsevier from Schwiedernoch et al. [78]. Top panel temperature of the solid structure of the catalytic monolith and the thermal insulation (675 (blue) to $925 \mathrm{~K}$ (red). Lower panel: gas-phase temperature (385-900 K), and species mole fractions $\left(\mathrm{CH}_{4}: 0.043-0.094, \mathrm{O}_{2}\right.$ : $0-0.055, \mathrm{H}_{2}: 0-0.0412, \mathrm{H}_{2} \mathrm{O}: 0-0.058, \mathrm{CO}: 0-0.042, \mathrm{CO}_{2}: 0-0.056$ ) in a single channel in the center of the monolith, red maximum, blue minimum. The time is set to zero when significant amounts of products can be observed after the reactor was heated up to the ignition temperature of $675 \mathrm{~K}$

at the very entrance region. Grunwaldt et al. studied the oxidation state of the catalyst during ignition of partial oxidation of methane over a $\mathrm{Pt} / \mathrm{Rh}$ catalyst in situ in miniaturized fixed-bed reactors by X-ray spectroscopy and infrared thermography. As shown in Fig. 6, the catalyst was found to be reduced during ignition starting from the downstream side of the flow reactor [129], which supports the finding of the modeling work (Figs. 3, 5).

In-operando modifications of the catalyst due to temporarily changing concentrations is a well-known phenomenon as revealed by many experiments. Modeling of this aspect on a reactor scale is rather challenging as soon as the modification goes beyond the variation of surface coverages. At first, the intrinsic kinetics of the chemical modification (e.g., oxidation, reduction, hydrogenation, and carbonization) of the bulk of the catalytic particle is not only difficult to measure and simulate from first-principles but also to implement in CFD models, because it depends on catalyst size, morphology, porosity. Currently, models use simple parameters such as an overall oxidation state or a capacity to model bulk modifications in reactor simulations. Attempts to include a spatial resolution of the state of 


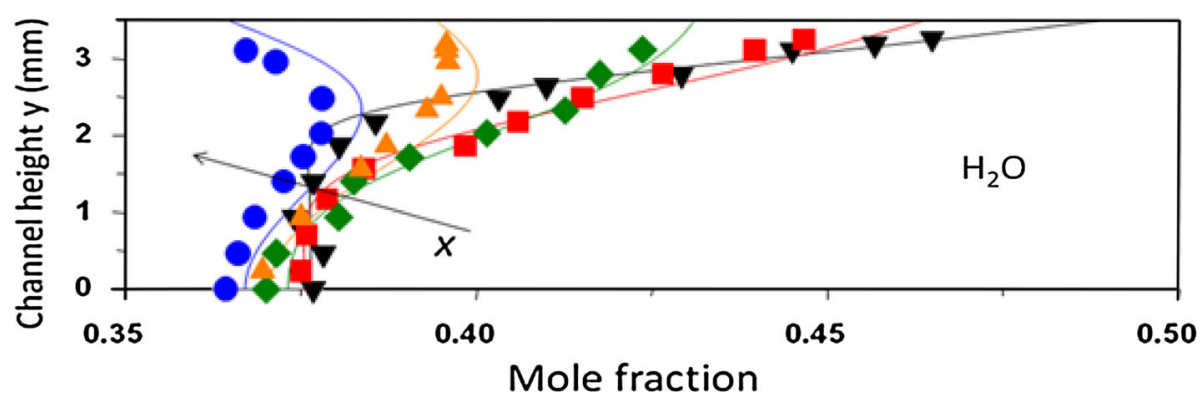

Fig. 4 Predicted (lines) and measured (symbols) steam profiles for autothermal reforming of methane over Rh at 6 bar, equivalence ratio of 4, and $38 \%$ steam addition, adapted with permission from Elsevier from Schneider et al. [80]. The profiles are given at different axial

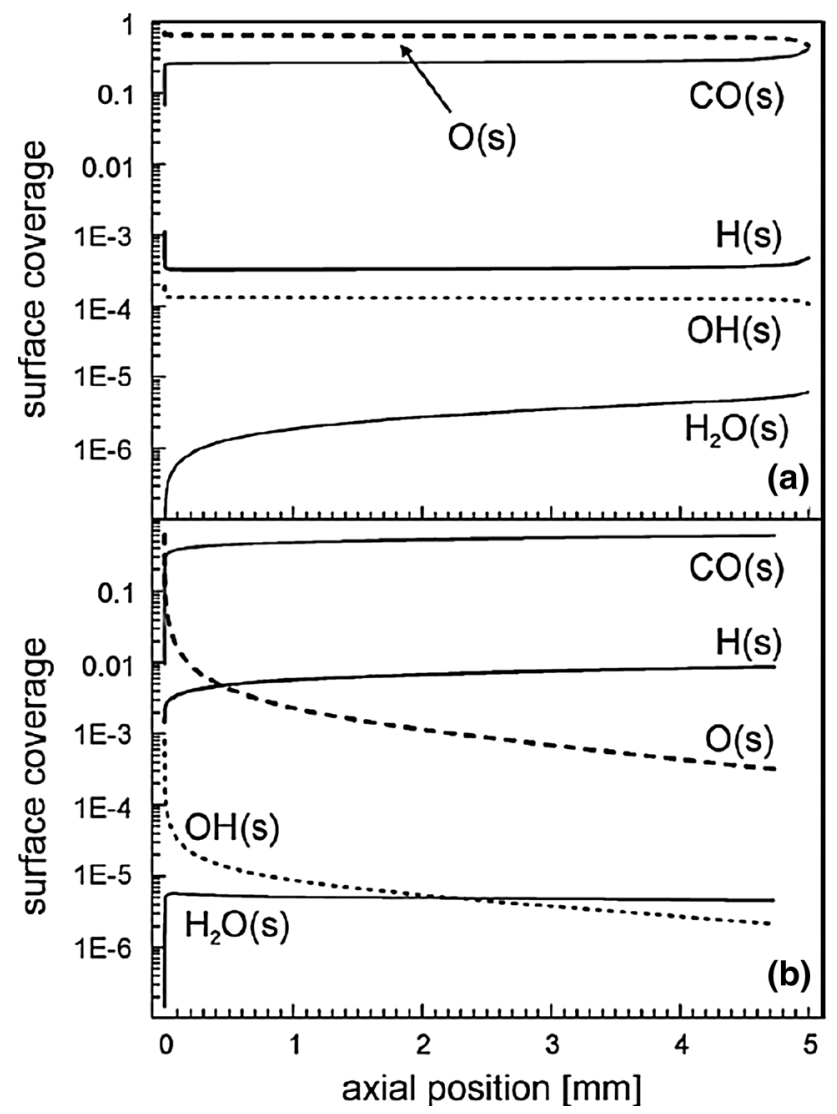

Fig. 5 Surface coverage of $\mathrm{CO}, \mathrm{O}, \mathrm{H}, \mathrm{OH}, \mathrm{H}_{2} \mathrm{O}$ on $\mathrm{Rh} 0.1 \mathrm{~s}$ (a) and $10 \mathrm{~s}$ (b) after light-off referring to Fig. 3; Figure reprinted with permission from Elsevier from Schwiedernoch et al. [78]

the catalytic particle are rare and only used for idealized particles.

\subsubsection{Deposits from the Gas-Phase: Gas-Phase Initiated Coking in Dry Reforming of Methane}

Coke formation on catalysts and walls of the reactor pipes are serious problems in many industrial reactors used for positions of $x=2$ (black triangle), 5 (red square), 9 (green diamond), 13 (orange triangle), 17 (blue sphere) $\mathrm{cm}$; the arrow denotes the flow direction $(\mathrm{x})$; catalytic wall at $\mathrm{y}=3.5 \mathrm{~mm}$, channel centerline at $\mathrm{y}=0$

instance for reforming, methanation, and cracking of hydrocarbons. Coke can be a source of catalyst deactivation and in severe cases leads to blocking of reactor tubes as well as physical disintegration of the catalyst support structure [81-84]. At high temperatures and elevated pressure, non-catalytic reactions in the gas phase play an essential role in the formation of higher hydrocarbons. Methane can be converted directly to hydrocarbons by thermally induced coupling reactions at high temperatures. The stepwise dehydrogenation of methane can be explained by free radical mechanisms. There are many pathways for gas-phase initiated coke formation on catalysts as sketched in Fig. 7 for methane pyrolysis [85]. Detailed reaction mechanisms have been developed to describe the molecular growth processes in the gas-phase by hundreds of elementary steps [86, 87]. Even though sticking coefficients for the many potential coke precursors in the gas-phase are difficult to estimate simple models for either adsorption of individual species or the coking growth rate have been developed and applied in the prediction of coking propensity of the catalytic system [88].

For instance, Kahle et al. [89] recently investigated why strong coking was observed in dry reforming of methane at the entrance of a laboratory pilot plant flow reactor. The results revealed that coking in the upper part of the catalyst bed and at the entrance of the reactor depends on the temperature. Olefins are formed in front of the catalytic bed due to the high temperature and pressure leading slowly but with increasing rate to coke formation inside the bed in the reforming of methane in the presence of carbon dioxide over $900{ }^{\circ} \mathrm{C}$ at 20 bar. Hydrogen addition can inhibit coke formation more efficiently than water addition. In this study, the model used an elementary-step reaction mechanism of 4,238 gas-phase reactions among 1,034 species and 58 heterogeneous reactions among eight gas-phase and 14 surface-adsorbed species. The study eventually led to a better positioning of the catalyst in the reformer tube. 

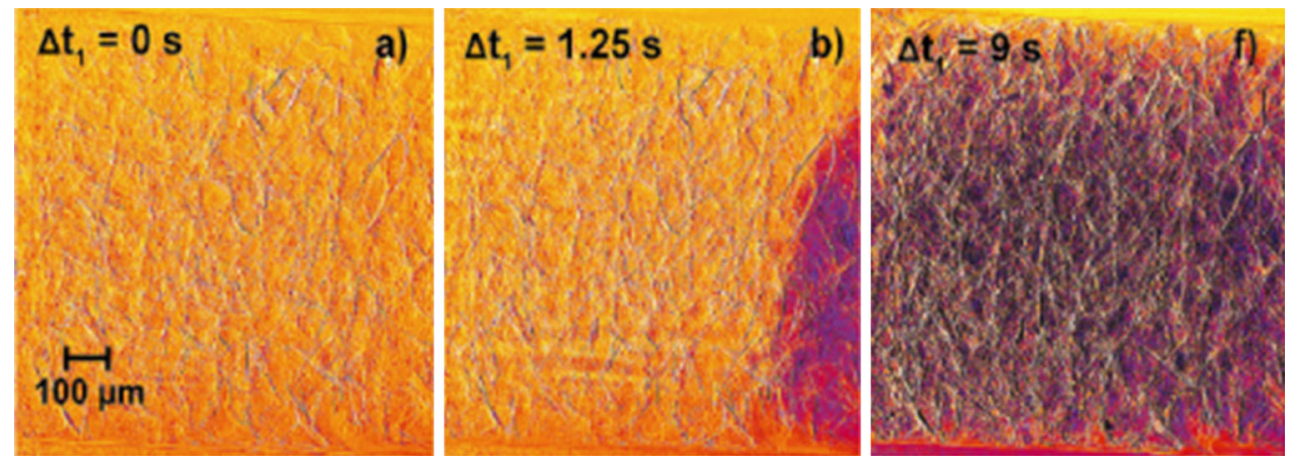

Fig. 6 Reduction of $\mathrm{Rh} / \mathrm{Pt} / \mathrm{Al}_{2} \mathrm{O}_{3}$ fixed bed catalyst during light-off of partial oxidation of methane observed by X-ray absorption (oxidized $=$ yellow-orange ; reduced $=$ red-violet ; Picture adapted with permission of American Chemical Society from Kimmerle et al. [129]

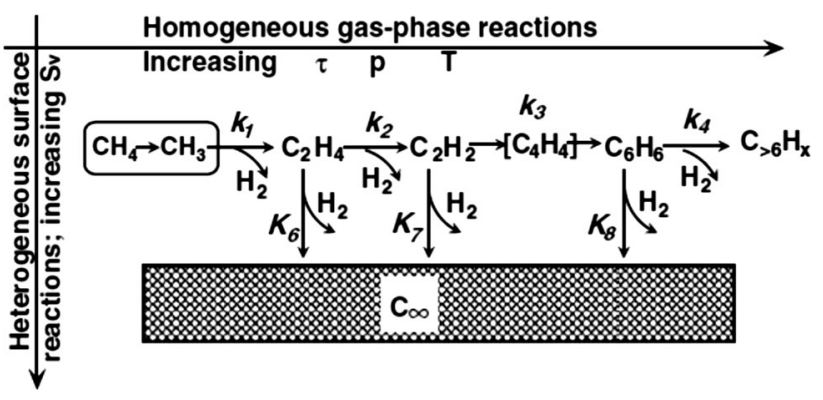

Fig. 7 Scheme of gas-phase initiated coke formation on catalytic particles $(\tau=$ residence time); Figure adapted with permission from Elsevier from Li et al. [85]

\subsubsection{Undesired Side Reactions in the Gas-Phase: Catalytic Reforming of Gasoline}

In contrast to the example above, where coke precursors were formed in front of the catalytic bed, they can also be formed in the gas-phase over the catalyst as shown in this example of modeling high-temperature catalysis. Catalytic reforming of logistic fuels such as gasoline, diesel, kerosene, and natural gas over Rh-based catalysts is a promising route for on-board production of hydrogen as fuel for auxiliary power units for more efficient and rather silent electricity supply in trucks, recreational vehicles, and airplanes. The demand of long-term stable operation of the reformer is challenged by the side-reaction in the gas-phase leading to coking of the pipes further downstream of the catalytic reactor. Therefore, Hartmann et al. studied the catalytic partial oxidation of the gasoline surrogate isooctane over a $\mathrm{Rh}$ coated monolith in terms of complex reaction mechanisms consisting of 7,193 homogeneous and 58 heterogeneous reactions among 857 gas phase and 17 surface species [90]. As Fig. 8 reveals the formation of hydrogen is mass transfer limited in the first section of the catalyst, the diffusion of oxygen being the rate-limiting process. The very low oxygen concentration at the catalyst entrance leads to some formation of hydrogen in a region, where the oxygen concentration in the gaseous bulk phase is still sufficiently high to promote total oxidation. In general, the reaction sequence is very similar to the behavior observed for light hydrocarbons by many groups [10, 78, 91-93]: after a short initial total oxidation zone leading to steam and $\mathrm{CO}_{2}$, the oxygen deficiency at the catalytic surface leads to the formation of hydrogen by steam reforming. Due to the high temperature of approximately $1,000{ }^{\circ} \mathrm{C}$, some remaining fuel is pyrolyzed by gasphase reactions to form the coke precursors ethylene and propylene (Fig. 8), a relatively slow process that is kinetically controlled but presenting a threat for any downstream system such as fuel cell devices [94-96].

\subsection{Mass Transport Interactions}

\subsubsection{Complex Flows Structures: Catalytic Fixed Bed Reactors}

Several attempts have been made to resolve the flow field in the actual configuration of fixed bed reactors, i.e. by a direct numerical simulation (DNS). Even though the governing equations are relatively simple for laminar flows, this usually can only be applied for small and periodic regions of the reactor due to the huge number of computational cells needed to resolve all existing boundary layers [97-103].

Dixon et al. took into account the actual structure of the catalytic fixed bed [104-107]. Having spheres as catalyst particles, the turbulent flow and heat transport in a periodic test cell with a tube-to-particle diameter ratio of 4 was simulated [108]. The turbulence was modeled by the Renormalization Group (RNG) $k-\varepsilon$ model [109], and two different wall functions (standard [110] and non-equilibrium) were applied to model the flow field near solid surfaces. Attempts to correlate the local wall heat flux with local properties of the flow field, such as velocity 
Fig. 8 Catalytic partial oxidation of iso-octane in $\mathrm{Rh}$ coated monolithic channels at $\mathrm{C} / \mathrm{O}=1.2$ and $800{ }^{\circ} \mathrm{C}$. Numerically predicted molar fractions of reactants, hydrogen, water (all for the initial section of $2 \mathrm{~mm}$ ) and the coke precursors propylene and ethylene (along the entire catalyst of $1 \mathrm{~cm}$ ). Flow direction is from left to right. Figure adapted with permission from Elsevier from Hartmann et al. [90]
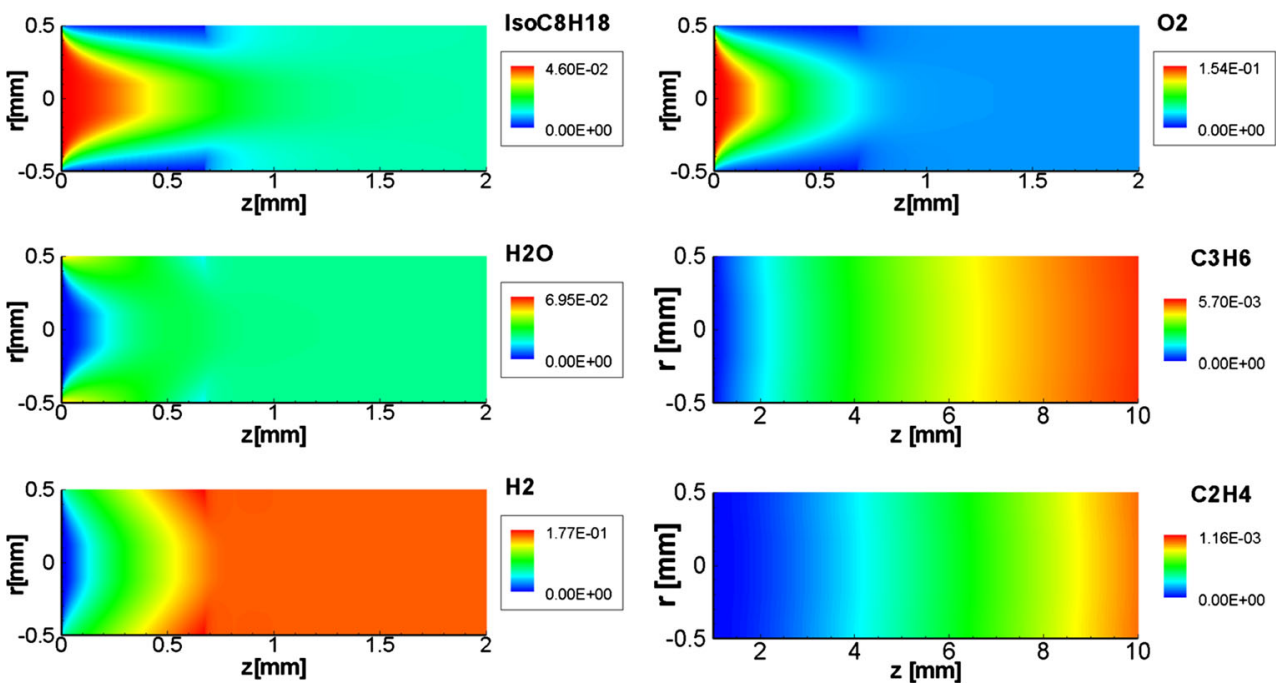

components, velocity gradients, and components of vorticity led to the conclusion that local heat transfer rates do not correlate statistically with the local flow field. Instead, a conceptual analysis was used to suggest that local patterns of wall heat flux are related to larger-scale flow structures in the bed. Recently, the same group studied the interplay of 3D transport and reaction occurring inside cylindrical pellets and in the gas flow around the pellets used for propane dehydrogenation to better understand catalyst deactivation by carbon deposition (Fig. 9) [111].

Lattice-Boltzmann-methods (LBM) have also been applied for a better understanding of fluid flow in complex reactor configurations [42, 43, 112]. The packing of spheres in cylindrical columns can be created either from experimental observations, such as magnetic resonance imaging (MRI), or by computer simulations. The created

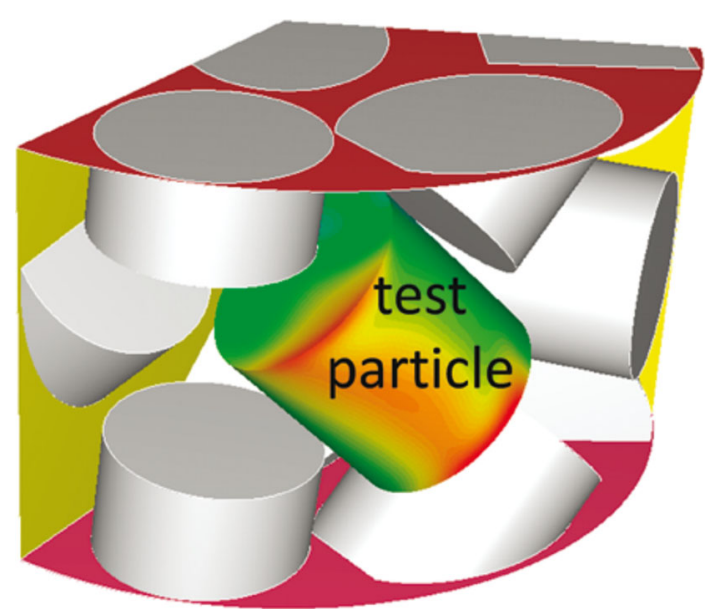

Fig. 9 Example of a direct numerical simulation of a fixed bed reactor with cylindrical packings showing contours of propane dehydrogenation rate on fresh catalyst; Figure adapted with permission from American Chemical Society from Dixon et al. [107] topology is then divided into a Cartesian grid, where individual elements are labeled as solid or fluid regions. A high resolution of the grid leads to accurate flow profiles. Zeiser et al. [43] generated the geometrical structures of the fixed bed with a Monte-Carlo method. This allowed to efficiently simulate the placement of randomly packed spheres in a cylinder and to obtain detailed information of statistical properties, such as the distribution of the void fraction. This geometrical information was the basis for subsequent numerical flow simulation using LBM. This approach allowed the prediction of the local fluid velocity distribution in the bed as well as the transport and rate of simple chemical reactions. Yuen et al. [112] studied correlations between local conversion and hydrodynamics in a 3D fixed-bed esterification process by applying a LBM and comparing its results with data from in situ magnetic resonance visualization techniques.

\subsubsection{Laminar Flow Fields in Channels: Capillary Sampling Technique}

There are wide varieties of catalytic reactors, in which the reactive mixtures flow through channel-like devices such as tubular chemical reactors, honeycomb structured monoliths, and foams. Depending on the channel size the flow field can be laminar or turbulent, or an initially turbulent flow field is laminarized in the entrance region of the channel. The latter situation can be found in most automotive catalytic converters.

In the last few years, a capillary sampling technique has become popular to measure axial species profiles in channel-like structures but also in fixed bed reactors in situ [10, $11,25,113]$. In this technique, a small amount of gas is sucked into a very thin capillary. The capillary is moved through the reactor providing axial species profiles. Hence, this technique can help to understand the reaction 
sequence. Compared to the non-invasive in situ laser spectroscopy method mentioned above, the capillary sampling technique is rather simple to handle, inexpensive, and provides very useful information rapidly. The cross sectional area of the thin capillary blocks only little, e.g. in our lab $3 \%$, of the channel's cross sectional area, through which the capillary is moved. However, the boundary layer formed on the capillary leads to a significant change in residence time and consequently in the species profiles (Fig. 10) [114]. In the case shown the residence time can be enlarged by more than a factor of two in worst case, i.e., when the capillary is positioned in the center of the channel and moved all the way through the channel (Fig. 11). This effect has to be taken into account in quantitative interpretation of the measured profiles $[114,115]$. This example shows how modeling the flow field in catalytic devices can be used to critically evaluate novel experimental techniques.

\subsubsection{Turbulent Flow: Catalytic Combustion Monoliths}

The flow in pipes with diameters ranging from a few centimeters up to meters is in most cases turbulent, guaranteeing a good mixing of the reactants. A fine resolution of flow field details is rarely of interest, and, aside from that, such a task exceeds today's computer capacities. Therefore, averaged equations and turbulence models are applied. Mantzaras et al. [116] applied the $k-\varepsilon$ model, a presumed (Gaussian) probability density function for gaseous reactions, and a laminar-like closure for surface reactions to study turbulent catalytically stabilized combustion of lean hydrogen-air mixtures in plane platinumcoated channels; a system very relevant for catalytic combustion stages in gas turbines, which reduces $\mathrm{NO}_{\mathrm{x}}$ emissions and increases efficiencies. They also examined different low-Reynolds number near-wall turbulence models and compared the numerically predicted results with data derived from planar laser-induced fluorescence measurements of $\mathrm{OH}$ radicals, Raman measurements of major species and laser doppler velocimetry measurements of local velocities and turbulence [50]. They found that discrepancies between predictions and measurements can be ascribed to the capacity of the various turbulence models to capture the strong flow laminarization induced by the heat transfer from the hot catalytic surfaces.

\subsubsection{Internal Diffusion: Three-Way Catalyst}

In the three-way catalyst (TWC), the catalytic material is dispersed in a washcoat on the inner channel wall of monolithic structures manufactured with various crosssectional shapes. Hayes et al. [28] and Mladenov et al. [29] used two- and three-dimensional, resp., simulations to study the impact of internal diffusion on the overall reaction rate. It was found that internal diffusion resistance, expressed in terms of an effectiveness factor, cannot be represented in terms of a unique curve using the generalized Thiele modulus approach. The most significant deviation occurs when the washcoat has a strong variation in thickness, as exemplarily shown in Fig. 12 by Hayes et al. [28]. For this converter, only a thin layer of the washcoat is needed in the corners of the channel for the catalytic conversion of the pollutants. The findings imply that the inner corners can be coated with an inexpensive catalystfree layer followed by a thin catalyst layer, the so-called zone-coating being technical practice today.

\subsection{Thermal Interactions}

The exponential dependence of the reaction rate on temperature calls for accurate predictions of the temperature profiles in catalytic reactors, which is a formidable task due

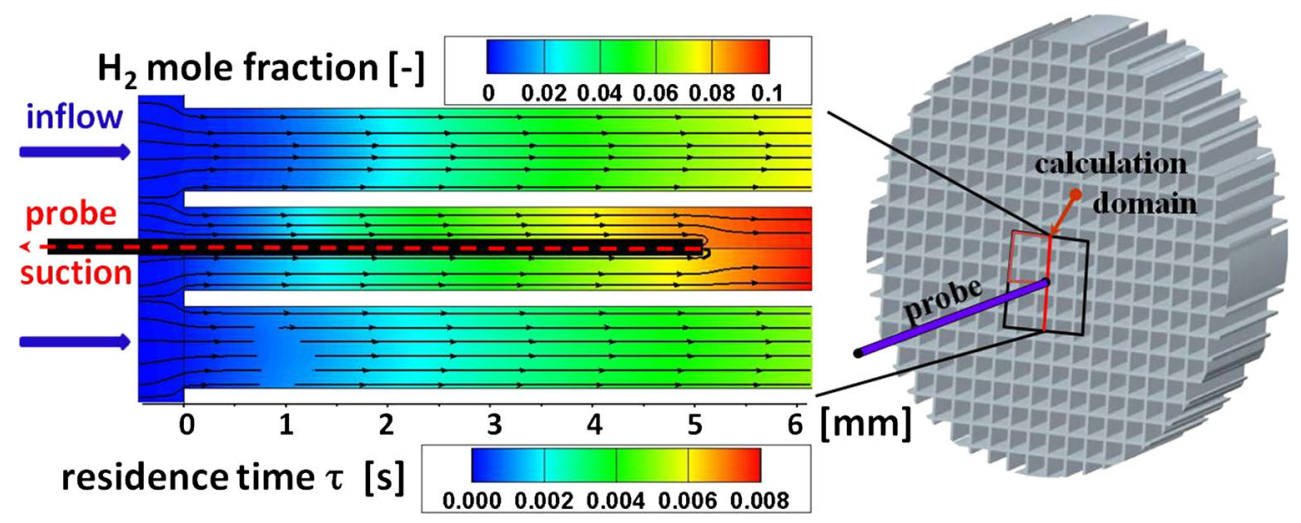

Fig. 10 Planar distributions of $\mathrm{H}_{2}$ (upper half) and residence time (lower half) of a three dimensional simulation of catalytic partial oxidation of methane in a $\mathrm{Rh} / \mathrm{Al}_{2} \mathrm{O}_{3}$ coated, $1 \mathrm{~cm}$ long honeycomb monolith. The probes is moved $5 \mathrm{~mm}$ into the channel in a central position. The streamlines depict the direction of the flow and show the suction of the capillary. Figure adapted with permission from Elsevier from Hettel et al. [114] 


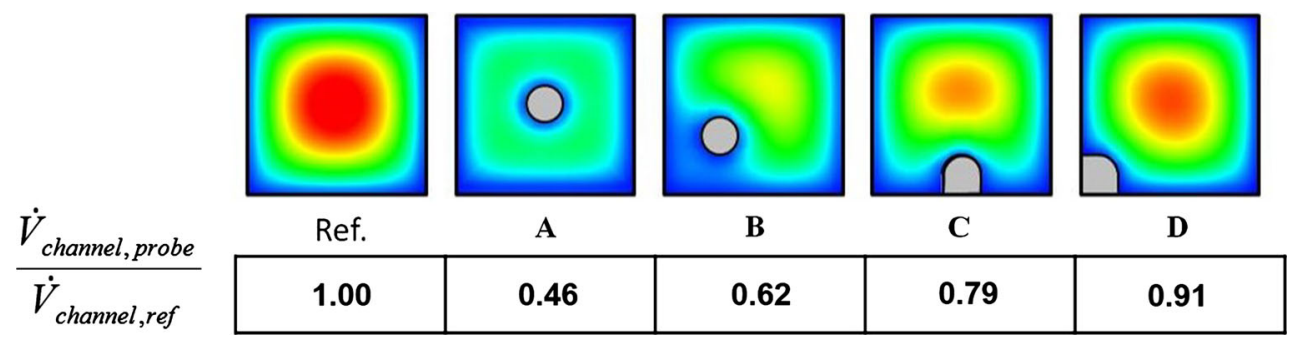

Fig. 11 Axial velocity profile at the outlet plane (top) and impact of the radial position of the capillary on volumetric flow rate (Table) computed by a three-dimensional simulation of catalytic partial

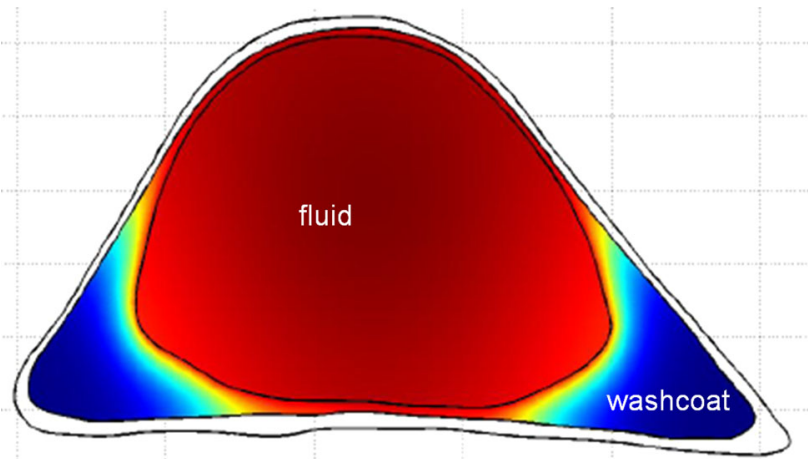

Fig. 12 Computed concentration of the pollutant in the cross-section of a monolithic catalyst with a "sinusoidal" channel and highly nonuniform washcoat at $700 \mathrm{~K}$. Adapted with permission from Elsevier from Hayes et al. [28]

to the variety in time scales of heat transport processes. In addition, the heat transfer at the outer boundaries of catalytic reactors, spatially varying inlet conditions, and catalyst coatings as well as aging effects demand heat transfer models that consider the entire catalytic reactor.

\subsubsection{Chemical Heat Release and Heat Loss: Faster Hydrogen Production at Shorter Residence Times}

Exemplarily, the high-temperature catalytic reforming of gasoline over a Rh-coated monolith is discussed again. Contraintuitively, shorter residence times increase fuel conversion and hydrogen yield in these reactors [117] up to rather high flow rates. Modeling the heterogeneously reacting flow in single channels coupled with heat transport in the gas-phase as well as in the solid structure helped to understand this phenomenon. The applied computer code DETCHEM ${ }^{\text {MONOLITH }}$ [72] combines a transient three-dimensional simulation of the solid structure with a 2D model of the single-channel flow field and detailed models for homogeneous gas-phase chemistry, heterogeneous surface chemistry as well as internal diffusion processes. In Fig. 13, the impact of flow rate on the temperature distribution in the monolithic sections of the short contact time reactor reveals that higher flow rates lead to an increase in oxidation of methane in a $\mathrm{Rh} / \mathrm{Al}_{2} \mathrm{O}_{3}$ coated, $1 \mathrm{~cm}$ long honeycomb monolith. The capillary is moved $10 \mathrm{~mm}$ into the channel. Figure adapted with permission from Elsevier from Hettel et al. [114]

temperature, conversion and consequently higher hydrogen yields [6]. With increasing flow rate the ratio of chemical heat release (exponential dependence on temperature) to heat loss (linear dependence for conductive but fourth order dependence for radiative losses) increases for the monolithic structures. Consequently, the temperature increases (Fig. 13), the rate of reaction increases, fuel conversion increases. In addition, higher temperature favor hydrogen yields from a thermodynamic point of view. Unfortunately, higher temperatures may also lead to undesired side-reactions in the gas-phase towards coke-precursors [96] as discussed above.

\subsubsection{Convective Heat Transport: Light-Off of Catalytic Converters}

Modeling the reduction of pollutant emission in automotive catalytic converters during a legislative driving cycle can

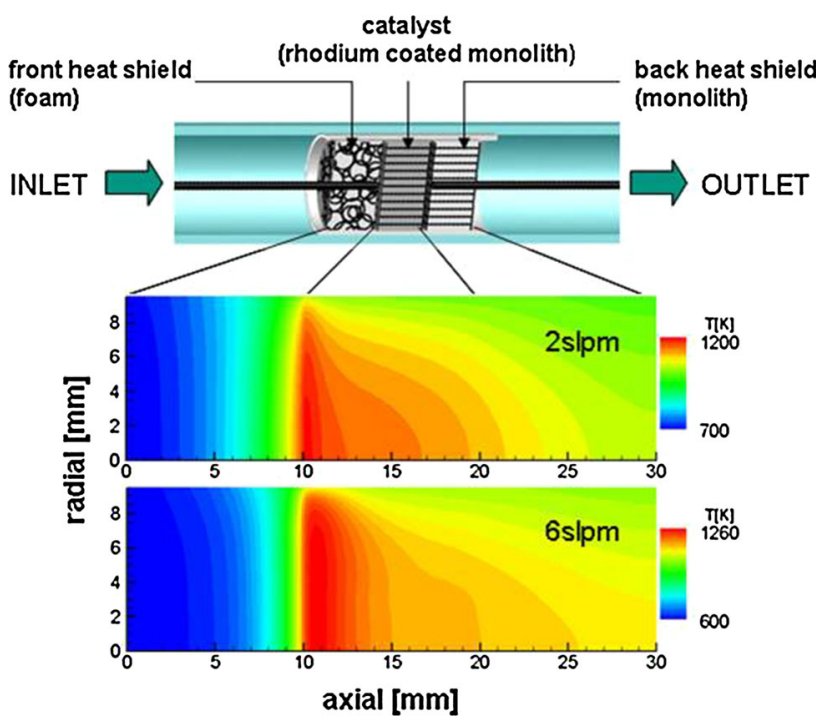

Fig. 13 Sketch (top) of the catalyst section of a reformer for logistic fuels (iso-octane as surrogate) with two heat shields and numerically predicted steady-state monolith temperature at flow rates of 2 slpm (middle) and 6 slpm (bottom). The symmetry axis of the monolith is at radial position of zero. Figure taken from Maier et al. [6] with permission from Elsevier 


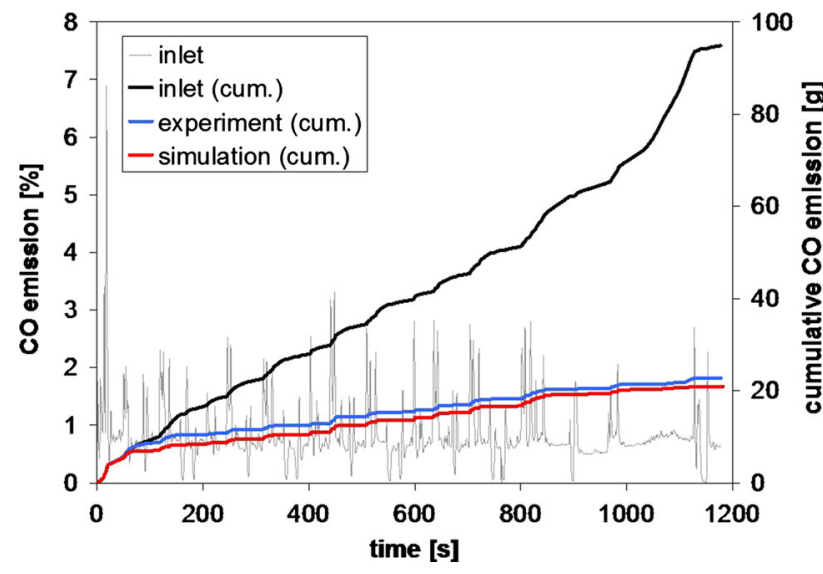

Fig. 14 Cumulated CO emissions in MVEG driving cycle of an automotive catalytic converter, simulation versus experiment. The continuously varying raw emissions (inlet, grey color) shown in the background serve as inlet conditions for the simulation. Figure taken from Tischer et al. [120]

substantially support development, design, and optimization of exhaust-gas after-treatment systems. Such simulations applying detailed reaction schemes for the usually multi-component and multi-functional catalyst are not straightforward [118]. Figure 14 presents a comparison of the experimental and computed time-resolved $\mathrm{CO}$ emission in a realistic automobile driving cycle [119-121]. The major reason for the very good agreement between simulation and experiment is the well-predicted ignition temperature after $\sim 1 \mathrm{~min}$ of operation. At first sight, an accurate dependence of the reaction rate on temperature seems to be the decisive sub-model. However, the prediction of the accurate temperature mainly depends on the correct description of the interaction of the incoming hot exhaust gases from the engine with the solid structure of the catalytic converter and its thermal insulation. Hence, accurate inlet and boundary conditions as well as thermal conductivities and heat capacities are eventually most influential for a good numerical prediction of the cumulative emissions.

\subsubsection{Chemical Release of Heat and Heat Transport: Ammonia Oxidation over Wire Gauzes}

Wire gauze reactors have been applied for high temperature catalytic reactions in industry for quite a long time. For example, ammonia is oxidized over $\mathrm{Pt} / \mathrm{Rh}$ wire gauzes to produce NO (Ostwald process), and similarly, $\mathrm{HCN}$ is synthesized by ammoxidation of methane (Andrussov process). Due to the complex 3D geometry, wire gauze reactors have been frequently treated by simpler two dimensional simulations [122, 123]. However, since mass and heat transport are the dominating processes in wire gauze reactors, simplifications of the flow field are risky.

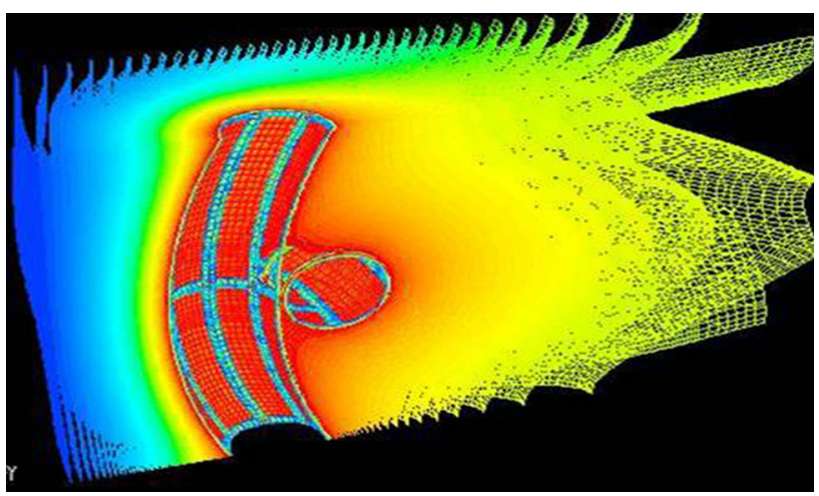

Fig. 15 Computed temperature profile $\left(\max .950{ }^{\circ} \mathrm{C}\right)$ around a $\mathrm{Pt} / \mathrm{Rh}$ wire gauze used for ammonia oxidation (Ostwald process); Figure reproduced with permission from Janardhanan and Deutschman [128]

Therefore, CFD studies were performed using 3D simulations of the flow field. The 3D flow field through knitted gauzes applied for ammonia oxidation was simulated by Neumann et al. [124]. Catalytic partial oxidation (CPOX) of light alkanes was also studied in wire gauze reactors. De Smet et al. [125] studied CPOX of methane with oxygen at atmospheric pressure in a continuous-flow reactor containing a single Pt metal gauze. They used 3D computations of simultaneous heat and mass transfer in case of a simple surface reaction on the gauze catalyst to derive intrinsic kinetics. This experiment was later simulated using even detailed surface and gas phase reaction schemes [126]. Figure 15 exemplarily shows the computed temperature profile around a $\mathrm{Pt} / \mathrm{Rh}$ wire gauze used for ammonia oxidation, which was carried out with the commercial CFD code FLUENT [127] coupled with a multistep surface reaction mechanism.

\section{Summary and Outlook}

The ultimate objectives of modeling and simulation of catalytic reactors are (1) a better understanding of the interactions of chemistry (heterogeneous and potential homogeneous reactions) and physics (mass and heat transport), (2) the support of reactor design and engineering, and (3) the optimization of operating conditions for the maximization of the yield of the desired product and minimization of undesired sideproducts. The numerous interactions between the catalytic surface reactions and the processes in the gas-phase play a central role. Depending on the chemical system, reactor configuration, and operating conditions, chemical, thermal, and mass-transfer induced interactions or often a combination of them will determine the observable reaction rate and reactor performance.

From a reaction engineering perspective, computational fluid dynamics simulations have matured into a powerful 
tool for understanding mass and heat transport in catalytic reactors. Initially, CFD calculations focused on a better understanding of mixing, mass transfer to enhance reaction rates, diffusion in porous media and heat transfer. Over the last decade, the flow field and heat transport models have also been coupled with models for heterogeneous chemical reactions. So far, most of these models are based on the mean field approximation, in which the local state of the surface is described by its coverage with adsorbed species averaged on a microscopic scale. The currently increasing research activities on surface reactions at practical conditions will certainly boost the application of CFD codes that combine fluid flow and chemistry. New insights into the complexity of heterogeneous catalysis, however, will also reveal the demand for more sophisticated chemistry models and their implementation into CFD simulations, which then requires sophisticated numerical algorithms and computer hardware. Hence, modeling the interactions of catalytic surface and surrounding gas-phase will remain a very active field and the implementation of more adequate and complex models will continue.

Despite this development, it should be noted that the results of the computations will always remain a reflection of the chemical and physical models and inlet and boundary conditions applied. The careful choice of the sub models for reaction kinetics, spatial dimension and resolution, turbulence, external and internal diffusion, thermal radiation etc. and the physical parameters and transport coefficients is a precondition for reliable simulation results. Furthermore, numerical algorithms never provide the accurate solution of the model equations but only an approximated one. Hence, error estimation is needed. Having these crucial issues in mind, computations can really serve as a powerful tool in understanding the behavior in catalytic reactors and in supporting the design and optimization of reactors and processes.

In this sense, understanding of the interaction of the catalyst with the surrounding gas-phase presents one of the top challenges and potentials in catalysis research today, aside from the development of new catalysts of course. The most powerful tool on this way is the combination of experimental techniques for the analyses of the state of the catalyst and the surrounding gas-phase in operando combined with numerical simulations using models based on the molecular behavior. Impressive progress has been made in the last 25 years but more is needed.

Acknowledgments The author would like to thank his former and current co-workers at the Karlsruhe Institute of Technology for their dedicated work that led to many of the results shown here. Financial support by the German Research Foundation (DFG), the Helmholtz Association, the European Union, and many partners in industry is gratefully acknowledged.

\section{References}

1. Heck RM, Farrauto RJ, Gulati ST (2002) Catalytic air pollution control, 2nd edn. Wiley-Interscience, New York

2. Hickman DA, Haupfear EA, Schmidt LD (1993) Synthesis gasformation by direct oxidation of methane over Rh monoliths. Catal Lett 17:223-237

3. Bodke AS, Schmidt LD (1999) On-line addition of catalyst in high-temperature reactors: high selectivity to olefins. Catal Lett 63:113-120

4. Sazonova NN, Simakov AV, Nikoro TA, Barannik GB, Lyakhova VF, Zheivot VI, Ismagilov ZR, Veringa H (1996) Selective catalytic oxidation of ammonia to nitrogen. React Kinet Catal Lett 57:71-79

5. Thormann J, Maier L, Pfeifer P, Kunz U, Deutschmann O, Schubert K (2009) Steam reforming of hexadecane over a $\mathrm{Rh} /$ $\mathrm{CeO}(2)$ catalyst in microchannels: experimental and numerical investigation. Int J Hydrogen Energy 34:5108-5120

6. Maier L, Hartmann M, Tischer S, Deutschmann O (2011) Interaction of heterogeneous and homogeneous kinetics with mass and heat transfer in catalytic reforming of logistic fuels. Combust Flame 158:796-808

7. Pfefferle LD, Pfefferle WC (1987) Catalysis in combustion. Catal Rev 29:219-264

8. Goralski CT, Schmidt LD (1996) Lean catalytic combustion of alkanes at short contact times. Catal Lett 42:47-55

9. Deutschmann O, Maier LI, Riedel U, Stroemman AH, Dibble RW (2000) Hydrogen assisted catalytic combustion of methane on platinum. Catal Today 59:141-150

10. Horn R, Degenstein NJ, Williams KA, Schmidt LD (2006) Spatial and temporal profiles in millisecond partial oxidation processes. Catal Lett 110:169-178

11. Donazzi A, Maestri M, Michael BC, Beretta A, Forzatti P, Groppi G, Tronconi E, Schmidt LD, Vlachos DG (2010) Microkinetic modeling of spatially resolved autothermal $\mathrm{CH}_{4}$ catalytic partial oxidation experiments over $\mathrm{Rh}$-coated foams. J Catal 275:270-279

12. J Koop, O Deutschmann (2007) SAE technical paper 2007-011142

13. Schmeisser V, Perez JDR, Tuttlies U, Eigenberger G (2007) Experimental results concerning the role of $\mathrm{Pt}, \mathrm{Rh}, \mathrm{Ba}, \mathrm{Ce}$ and $\mathrm{Al}_{2} \mathrm{O}_{3}$ on $\mathrm{NO}_{\mathrm{x}}$-storage catalyst behaviour. Top Catal 42-43:15-19

14. Appel C, Mantzaras J, Schaeren R, Bombach R, Inauen A, Kaeppeli B, Hemmerling B, Stampanoni A (2002) An experimental and numerical investigation of homogeneous ignition in catalytically stabilized combustion of hydrogen/air mixtures over platinum. Combust Flame 128:340-368

15. Maruta K, Takeda K, Ahn J, Borer K, Sitzki L, Ronney PD, Deutschmann O (2002) Extinction limits of catalytic combustion in microchannels. Proc Combust Inst 29:957-963

16. Song CS (2002) Fuel processing for low-temperature and hightemperature fuel cells: challenges, and opportunities for sustainable development in the 21st century. Catal Today 77:17-49

17. Meusel I, Hoffmann J, Hartmann J, Heemeier M, Baumer M, Libuda J, Freund HJ (2001) The interaction of oxygen with alumina-supported palladium particles. Catal Lett 71:5-13

18. Hannemann S, Grunwaldt JD, Kimmerle B, Baiker A, Boye P, Schroer C (2009) Axial changes of catalyst structure and temperature in a fixed-bed microreactor during noble metal catalysed partial oxidation of methane. Top Catal 52:1360-1370

19. Hauptmann W, Votsmeier M, Gieshoff J, Drochner A, Vogel H (2009) Inverse hysteresis during the NO oxidation on Pt under lean conditions. Appl Catal B Environ 93:22-29 
20. Schulz H (2014) Selforganization in Fischer-Tropsch synthesis with iron- and cobalt catalysts. Catal Today 228:113-122

21. Lietti L, Forzatti P, Nova I, Tronconi E (2001) NOx storage reduction over Pt-Ba/gamma- $\mathrm{Al}_{2} \mathrm{O}_{3}$ catalyst. J Catal 204:175-191

22. Deutschmann O, Konstandopoulos AG (2010) Catalytic technology for soot and gaseous pollution control. In: Lackner M, Winter F, Agarwal A (eds) Handbook of combustion. Vol 2: combustion diagnostics and pollutants. Wiley-VCH Verlag, Weinheim, pp 465-510

23. Walters KM, Dean AM, Zhu HY, Kee RJ (2003) Homogeneous kinetics and equilibrium predictions of coking propensity in the anode channels of direct oxidation solid-oxide fuel cells using dry natural gas. J Power Sources 123:182-189

24. Donazzi A, Livio D, Maestri M, Beretta A, Groppi G, Tronconi E, Forzatti P (2011) Synergy of homogeneous and heterogeneous chemistry probed by in situ spatially resolved measurements of temperature and composition. Angew Chem Int Ed 50:3943-3946

25. Livio D, Diehm C, Donazzi A, Beretta A, Deutschmann O (2013) Catalytic partial oxidation of ethanol over $\mathrm{Rh} / \mathrm{Al}_{2} \mathrm{O}_{3}$ : spatially resolved temperature and concentration profiles. Appl Catal A General 467:530-541

26. Zerkle DK, Allendorf MD, Wolf M, Deutschmann O (2000) Understanding homogeneous and heterogeneous contributions to the platinum-catalyzed partial oxidation of ethane in a shortcontact-time reactor. J Catal 196:18-39

27. Beretta A, Forzatti P (2001) High-temperature and short-contact-time oxidative dehydrogenation of ethane in the presence of $\mathrm{Pt} / \mathrm{Al}_{2} \mathrm{O}_{3}$ and $\mathrm{BaMnAl}_{11} \mathrm{O}_{19}$ catalysts. J Catal 200:45-58

28. Hayes RE, Liu B, Moxom R, Votsmeier M (2004) The effect of washcoat geometry on mass transfer in monolith reactors. Chem Eng Sci 59:3169-3181

29. Mladenov N, Koop J, Tischer S, Deutschmann O (2010) Modeling of transport and chemistry in channel flows of automotive catalytic converters. Chem Eng Sci 65:812-826

30. Deutschmann O (2011) Modeling and simulation of heterogeneous catalytic reactions: from the molecular process to the technical system. Wiley-VCH, Weinheim

31. Jakobsen HA (2008) Chemical reactor modeling: multiphase reactive flows. Springer-Verlag, Heidelberg

32. Crowe CT, Schwarzkopf JD, Sommerfeld M, Tsuji Y (1998) Multiphase flows with droplets and particles. CRC Press, New York

33. Ishii M, Hibiki T (2006) Thermo-fluid dynamics of two-phase flow. Springer, New York

34. Kee RJ, Coltrin ME, Glarborg P (2003) Chemically reacting flow. Wiley-Interscience, New York

35. Bird RB, Stewart WE, Lightfoot EN (2001) Transport phenomena, 2nd edn. Wiley, New York

36. Patankar SV (1980) Numerical heat transfer and fluid flow. McGraw-Hill, New York

37. Warnatz J, Dibble RW, Maas U (1996) Combustion, physical and chemical fundamentals, modeling and simulation, experiments, pollutant formation. Springer-Verlag, New York

38. Hayes RE, Kolaczkowski ST (1997) Introduction to catalytic combustion. Gordon and Breach Science Publ, Amsterdam

39. Succi S (2001) The lattice Boltzmann equation for fluid dynamics and beyond. Oxford University Press, Oxford

40. Arcidiacono S, Mantzaras J, Karlin IV (2008) Lattice Boltzmann simulation of catalytic reactions. Phys Rev E 78:046711

41. Sullivan SP, Sani FM, Johns ML, Gladden LF (2005) Simulation of packed bed reactors using lattice Boltzmann methods. Chem Eng Sci 60:3405-3418

42. Freund H, Zeiser T, Huber F, Klemm E, Brenner G, Durst F, Emig G (2003) Numerical simulations of single phase reacting flows in randomly packed fixed-bed reactors and experimental validation. Chem Eng Sci 58:903-910

43. Zeiser T, Lammers P, Klemm E, Li YW, Bernsdorf J, Brenner G (2001) CFD-calculation of flow, dispersion and reaction in a catalyst filled tube by the lattice Boltzmann method. Chem Eng Sci 56:1697-1704

44. Hirschfelder JO, Curtiss CF, Bird RB (1964) Molecular theory of gases and liquids, Rev edn. Wiley, New York

45. Laudner BE, Spalding DB (1972) Mathematical models of turbulence. Academic Press, London/New York

46. Libby PA, Williams FA (1993) Turbulent reactive flow. Academic Press, London

47. Fox RO (2003) Computational models for turbulent reacting flows. Cambridge University Press, Cambridge

48. Pope SB (1985) PDF methods for turbulent reactive flows. Prog Energy Combust Sci 11:119-192

49. Gutheil E, Bockhorn H (1987) The effect of multi-dimensional PDFs in turbulent reactive flows at moderate Damköhler number. Physicochem Hydrodyn 9:525

50. Appel C, Mantzaras J, Schaeren R, Bombach R, Kaeppeli B, Inauen A (2003) An experimental and numerical investigation of turbulent catalytically stabilized channel flow combustion of hydrogen/air mixtures over platinum. Proc Combust Inst 29:1031-1038

51. Marchisio DL, Fox RO (2007) Multiphase reacting flows: modelling and simulation. Springer-Verlag, New York

52. Marchisio DL, Fox RO (2013) Computational models for polydisperse particulate and multiphase systems. Cambridge University Press, Cambridge

53. Aris R (1975) The mathematical theory of diffusion and reaction in permeable catalysts. Clarendon Press, Oxford

54. Keil F (1999) Diffusion und Chemische Reaktionen in der GasFeststoff-Katalyse. Springer-Verlag, Berlin

55. Keil FJ (2000) Diffusion and reaction in porous networks. Catal Today 53:245-258

56. Bey O, Eigenberger G (1997) Fluid flow through catalyst filled tubes. Chem Eng Sci 52:1365-1376

57. Giese M, Rottschafer K, Vortmeyer D (1998) Measured and modeled superficial flow profiles in packed beds with liquid flow. AIChE J 44:484-490

58. Winterberg M, Tsotsas E, Krischke A, Vortmeyer D (2000) A simple and coherent set of coefficients for modelling of heat and mass transport with and without chemical reaction in tubes filled with spheres. Chem Eng Sci 55:967-979

59. Gladden LF (2003) Recent advances in MRI studies of chemical reactors: ultrafast imaging of multiphase flows. Top Catal 24:19-28

60. ME Coltrin, RJ Kee, FM Rupley (1991) SURFACE CHEMKIN (Version 4.0): a fortran package for analyzing heterogeneous chemical kinetics at a solid-surface-gas-phase interface, SAND91-8003B, Sandia National Laboratories

61. Boll W, Tischer S, Deutschmann O (2010) Loading and aging effects in exhaust gas after-treatment catalysts with $\mathrm{Pt}$ as active component. Ind Eng Chem Res 49:10303-10310

62. Kang SB, Kwon HJ, Nam IS, Song YI, Oh S (2011) Activity function for describing alteration of TWC performance over Pdonly TWCs by catalyst mileage. Ind Eng Chem Res 50(9):5499-5509

63. Deutschmann O, Schmidt R, Behrendt F, Warnatz J (1996) Numerical modeling of catalytic ignition. Proc Combust Inst 26:1747-1754

64. Raja LL, Kee RJ, Petzold LR (1998) Simulation of the transient, compressible, gas-dynamic, behavior of catalytic-combustion ignition in stagnation flows. Proc Combust Inst 27:2249-2257

65. Papadias D, Edsberg L, Björnbom PH (2000) Simplified method of effectiveness factor calculations for irregular geometries of 
washcoats. A general case in a $3 \mathrm{D}$ concentration field. Catal Today 60:11-20

66. Mason E, Malinauskas A (1983) Gas transport in porous media: the dusty-gas model. American Elsevier, New York

67. Coltrin ME, Kee RJ, Rupley FM (1991) Surface Chemkin: a general formalism and software for analyzing heterogeneous chemical kinetics at a gas-surface interface. Int $\mathrm{J}$ Chem Kinet 23:1111-1128

68. Warnatz J (1992) Resolution of gas phase and surface combustion chemistry into elementary reactions (invited lecture). Proc Combust Inst 24:553-579

69. RJ Kee, FM Rupley, JA Miller (1998) CHEMKIN-II: a fortran chemical kinetics package for the analysis of gas-phase chemical kinetics, SAND89-8009, Sandia National Laboratories

70. RJ Kee, FM Rupley, JA Miller, ME Coltrin, JF Grcar, E Meeks, HK Moffat, AE Lutz, G Dixon-Lewis, MD Smooke, J Warnatz, GH Evans, RS Larson, RE Mitchell, LR Petzold, WC Reynolds, M Caracotsios, WE Stewart, P Glarborg, C Wang, O Adigun (2001) CHEMKIN collection, Release 3.6, Reaction Design, Inc., San Diego

71. DG Goodwin (2003) CANTERA. An open-source, extensible software suite for CVD process simulation. www.cantera.org

72. O Deutschmann, S Tischer, C Correa, D Chatterjee, S Kleditzsch, VM Janardhanan, N Mladenov, HD Minh, H Karadeniz, M Hettel (2014) DETCHEM software package, Version 2.5, www.detchem.com, Karlsruhe

73. O Deutschmann (2007) Computational fluid dynamics simulation of catalytic reactors: chapter 6.6. In: HKG Ertl, F Schüth, J Weitkamp (ed) Handbook of heterogeneous catalysis, 2nd edn. Wiley-VCH, New York

74. Mhadeshwar AB, Wang H, Vlachos DG (2003) Thermodynamic consistency in microkinetic development of surface reaction mechanisms. J Phys Chem B 107:12721-12733

75. Maier L, Schädel B, Herrera Delgado K, Tischer S, Deutschmann O (2011) Steam reforming of methane over nickel: development of a multi-step surface reaction mechanism. Top Catal 54:845-858

76. Dean AM (1990) Detailed kinetic modeling of autocatalysis in methane pyrolysis. J Phys Chem 94:1432-1439

77. Dente M, Ranzi E, Goossens AG (1979) Detailed prediction of olefin yields from hydrocarbon pyrolysis through a fundamental simulation-model (SPYRO). Comput Chem Eng 3:61-75

78. Schwiedernoch R, Tischer S, Correa C, Deutschmann O (2003) Experimental and numerical study on the transient behavior of partial oxidation of methane in a catalytic, monolith. Chem Eng Sci 58:633-642

79. Tischer S, Deutschmann O (2005) Recent advances in numerical modeling of catalytic monolith reactors. Catal Today 105: 407-413

80. Schneider A, Mantzaras J, Bombach R, Schenker S, Tylli N, Jansohn P (2007) Laser induced fluorescence of formaldehyde and Raman measurements of major species during partial catalytic oxidation of methane with large $\mathrm{H}_{2} \mathrm{O}$ and $\mathrm{CO}_{2}$ dilution at pressures up to 10 bar. Proc Combust Inst 31:1973-1981

81. Alstrup I, Tavares MT, Bernardo CA, Sorensen O, RostrupNielsen JR (1998) Carbon formation on nickel and nickel-copper alloy catalysts. Mater Corros 49:367-372

82. Blekkan EA, Myrstad R, Olsvik O, Rokstad OA (1992) Characterization of tars and coke formed during the pyrolysis of methane in a tubular reactor. Carbon 30:665-673

83. Bartholomew CH (1982) Carbon deposition in steam reforming and methanation. Catal Rev 24:67-112

84. Rostrup-Nielsen JR (1984) Catalytic Steam Reforming. In: Anderson JR, Boudart M (eds) catalysis science and technology. Springer-Verlag, New York
85. Li A, Norinaga K, Zhang WG, Deutschmann O (2008) Modeling and simulation of materials synthesis: chemical vapor deposition and infiltration of pyrolytic carbon. Compos. Sci. Technol. 68:1097-1104

86. Norinaga K, Deutschmann O (2007) Detailed kinetic modeling of gas-phase reactions in the chemical vapor deposition of carbon from light hydrocarbons. Ind Eng Chem Res 46:3547-3557

87. Mims CA, Mauti R, Dean AM, Rose KD (1994) Radical chemistry in methane oxidative coupling: tracing of ethylene secondary reactions with computer models and isotopes. J Phys Chem 98:13357-13372

88. Essmann C, Maier L, Li A, Tischer S, Deutschmann O (2014) Natural gas steam reforming over rhodium/alumina catalysts: experimental and numerical study of the carbon deposition from ethylene and carbon monoxide. Ind Eng Chem Res 53:12270-12278

89. Kahle LCS, Roussiere T, Maier L, Delgado KH, Wasserschaff G, Schunk SA, Deutschmann O (2013) Methane dry reforming at high temperature and elevated pressure: impact of gas-phase reactions (vol 52, pg 11920. Ind Eng Chem Res 52(2013): 14727-14727

90. Hartmann M, Maier L, Minh HD, Deutschmann O (2010) Catalytic partial oxidation of iso-octane over rhodium catalysts: an experimental, modeling, and simulation study. Combust Flame 157:1771-1782

91. Karagiannidis S, Mantzaras J, Jackson G, Boulouchos K (2007) Hetero-/homogeneous combustion and stability maps in methane-fueled catalytic microreactors. Proc Combust Inst 31:3309-3317

92. Maestri M, Vlachos DG, Beretta A, Forzatti P, Groppi G, Tronconi E (2009) Dominant reaction pathways in the catalytic partial oxidation of $\mathrm{CH}_{4}$ on $\mathrm{Rh}$. Top Catal 52:1983-1988

93. Beretta A, Groppi G, Lualdi M, Tavazzi I, Forzatti P (2009) Experimental and modeling analysis of methane partial oxidation: transient and steady-state behavior of rh-coated honeycomb monoliths. Ind Eng Chem Res 48:3825-3836

94. Hartmann M, Kaltschmitt T, Deutschmann O (2009) Catalytic partial oxidation of higher hydrocarbon fuel components on $\mathrm{Rh} /$ $\mathrm{Al}_{2} \mathrm{O}_{3}$ coated honeycomb monoliths. Catal Today 147:S204-S209

95. Hebben N, Diehm C, Deutschmann O (2010) Catalytic partial oxidation of ethanol on alumina-supported Rh catalysts: an experimental study. Appl Catal A 388:225-231

96. Kaltschmitt T, Maier L, Deutschmann O (2011) Influence of gas-phase reactions on catalytic reforming of isooctane. Proc Combust Inst 33:3138-3177

97. Sorensen JP, Stewart WE (1974) Computation of forced-convection in slow flow through ducts and packed-beds. 3. Heat and mass-transfer in a simple cubic array of spheres. Chem Eng Sci 29:827-832

98. Dalman MT, Merkin JH, McGreavy C (1986) Fluid-flow and heat-transfer past 2 spheres in a cylindrical tube. Comput Fluids $14: 267-281$

99. Lloyd B, Boehm R (1994) Flow and heat-transfer around a linear-array of spheres. Numer Heat Tranf A Appl 26:237-252

100. Debus K, Nirschl H, Delgado A, Denk V (1998) Numerical simulation of local momentum transfer in beds of spherical particles. Chem Ing Tech 70:415-418

101. Logtenberg SA, Nijemeisland M, Dixon AG (1999) Computational fluid dynamics simulations of fluid flow and heat transfer at the wall-particle contact points in a fixed-bed reactor. Chem Eng Sci 54:2433-2439

102. Calis HPA, Nijenhuis J, Paikert BC, Dautzenberg FM, van den Bleek CM (2001) CFD modelling and experimental validation of pressure drop and flow profile in a novel structured catalytic reactor packing. Chem Eng Sci 56:1713-1720 
103. Petre CF, Larachi F, Iliuta I, Grandjean BPA (2003) Pressure drop through structured packings: breakdown into the contributing mechanisms by CFD modeling. Chem Eng Sci 58: $163-177$

104. Dixon AG, Taskin ME, Nijemeisland M, Stitt EH (2008) Wallto-particle heat transfer in steam reformer tubes: CFD comparison of catalyst particles. Chem Eng Sci 63:2219-2224

105. Dixon AG, Taskin ME, Stitt EH, Nijemeisland M (2007) 3D CFD simulations of steam reforming with resolved intraparticle reaction and gradients. Chem Eng Sci 62:4963-4966

106. Dixon AG, Nijemeisland M, Stitt EH (2005) CFD study of heat transfer near and at the wall of a fixed bed reactor tube: effect of wall conduction. Ind Eng Chem Res 44:6342-6353

107. Behnam M, Dixon AG, Nijemeisland M, Stitt EH (2005) Catalyst deactivation in 3D CFD resolved particle simulations of propane dehydrogenation. Ind Eng Chem Res 49:10641-10650

108. Nijemeisland M, Dixon AG (2004) CFD study of fluid flow and wall heat transfer in a fixed bed of spheres. AIChE J 50:906-921

109. Yakhot V, Orszag SA (1986) Renormalization-group analysis of turbulence. Phys Rev Lett 57:1722-1724

110. Laudner BE, Spalding DB (1974) The numerical computation of turbulent flows. Comput Methods Appl Math Eng 3:169-289

111. Behnam M, Dixon AG, Nijemeisland M, Stitt EH (2010) Catalyst deactivation in 3D CFD resolved particle simulations of propane dehydrogenation. Ind Eng Chem Res 49:10641-10650

112. Yuen EHL, Sederman AJ, Sani F, Alexander P, Gladden LF (2003) Correlations between local conversion and hydrodynamics in a 3-D fixed-bed esterification process: an MRI and lattice-Boltzmann study. Chem Eng Sci 58:613-619

113. Sa J, Fernandes DLA, Aiouache F, Goguet A, Hardacre C, Lundie D, Naeem W, Partridge WP, Stere C (2010) SpaciMS: spatial and temporal operando resolution of reactions within catalytic monoliths. Analyst 135:2260-2272

114. Hettel M, Diehm C, Torkashvand B, Deutschmann O (2013) Critical evaluation of in situ probe techniques for catalytic honeycomb monoliths. Catal Today 216:2-10

115. M Hettel, C Diehm, O Deutschmann (2014) Answer to the comment from Goguet et al. to the paper "The Critical evaluation of in situ probe techniques for catalytic honeycomb monoliths" by Hettel et al. Catal Today 236: 209-213

116. Mantzaras J, Appel C, Benz P, Dogwiler U (2000) Numerical modelling of turbulent catalytically stabilized channel flow combustion. Catal Today 59:3-17

117. Hartmann M, Maier L, Deutschmann O (2011) Hydrogen production by catalytic partial oxidation of iso-octane at varying flow rate and fuel/oxygen ratio: from detailed kinetics to reactor behavior. Appl Catal A 391:144-152

118. J Windmann, J Braun, P Zacke, S Tischer, O Deutschmann, J Warnatz (2003) Impact of the inlet flow distribution on the lightoff behavior of a 3-way catalytic converter. SAE technical paper, 2003-01-0937

119. J Braun, T Hauber, H Többen, J Windmann, P Zacke, D Chatterjee, C Correa, O Deutschmann, L Maier, S Tischer, J Warnatz (2002) Three-dimensional simulation of the transient behavior of a three-way catalytic converter. SAE technical paper, 2002-01-0065

120. S Tischer, Y Jiang, KW Hughes, MD Patil, M Murtagh (2007) Three-way-catalyst modeling-a comparison of $1 \mathrm{D}$ and 2D simulations. SAE technical paper 2007-01-1071

121. Koop J, Deutschmann O (2009) Detailed surface reaction mechanism for Pt-catalyzed abatement of automotive exhaust gases. Appl Catal B 91:47-58

122. Zakharov VP, Zolotarskii IA, Kuzmin VA (2003) CFD simulation of "gauze pad-honeycomb" catalytic system. Chem Eng J 91:249-255

123. RP ÓConnor, LD Schmidt, O Deutschmann (2002) Simulating cyclohexane millisecond oxidation: coupled chemistry and fluid dynamics. Aiche J 48: 1241-1256

124. Neumann J, Golitzer H, Heywood A, Ticu I (2002) dmc(2)'s MKS Modulares Katalysator System (TM): an advanceed catalyst technology for ammonia oxidation. Rev Chim 53:721-724

125. de Smet CRH, de Croon MHJM, Berger RJ, Marin GB, Schouten JC (1999) An experimental reactor to study the intrinsic kinetics of catalytic partial oxidation of methane in the presence of heat-transport limitations. Appl Catal A 187:33-48

126. Quiceno R, Pérez-Ramirez J, Warnatz J, Deutschmann O (2006) Modeling of catalytic partial oxidation of methane in a single gauze reactor: detailed gas and surface chemistry coupled with 3D flow field simulation. Appl Catal A 303:166-176

127. FLUENT, 4.4 ed, Fluent Inc. Lebanon, New Hampshire, 1997

128. Janardhanan VM, Deutschman O (2011) Computational fluid dynamics of catalytic reactors. In: Deutschman O (ed) Modeling and simulation of heterogeneous catalytic reactions: from the molecular process to the technical system. WILEY-VCH, Weinheim

129. Kimmerle B, Grunwaldt J-D, Baiker A, Glatzel P, Boye P, Stephan S, Schroer CG (2009) Visualizing a catalyst at work during the ignition of the catalytic partial oxidation of methane. J Phys Chem C 113:3037-3040 